\title{
Oligodendrocyte, Astrocyte, and Microglia Crosstalk in Myelin Development, Damage, and Repair
}

\author{
Helena S. Domingues ${ }^{1,2+}$, Camila C. Portugal ${ }^{1,2+}$, Renato Socodato ${ }^{1,2+}$ and \\ João B. Relvas ${ }^{1,2 *}$ \\ ${ }^{1}$ Glial Cell Biology Group, Instituto de Biologia Molecular e Celular, Universidade do Porto, Porto, Portugal, ${ }^{2}$ Glial Cell Biology \\ Group, Instituto de Investigação e Inovação em Saúde (ISS), Universidade do Porto, Porto, Portugal
}

OPEN ACCESS

Edited by:

Adelaide Fernandes,

University of Lisbon, Portugal

Reviewed by:

Amit Agarwal,

Johns Hopkins University, USA

Sue C. Barnett,

University of Glasgow, UK

Alban Gaultier,

University of Virginia, USA

*Correspondence:

João B. Relvas

jrelvas@ibmc.up.pt

${ }^{\dagger}$ These authors have contributed equally to this work.

Specialty section:

This article was submitted to

Molecular Medicine,

a section of the journal

Frontiers in Cell and Developmental

Biology

Received: 31 March 2016

Accepted: 15 June 2016

Published: 28 June 2016

Citation:

Domingues HS, Portugal CC,

Socodato $R$ and Relvas JB (2016)

Oligodendrocyte, Astrocyte, and

Microglia Crosstalk in Myelin

Development, Damage, and Repair.

Front. Cell Dev. Biol. 4:71

doi: 10.3389/fcell.2016.00071
Oligodendrocytes are the myelinating glia of the central nervous system. Myelination of axons allows rapid saltatory conduction of nerve impulses and contributes to axonal integrity. Devastating neurological deficits caused by demyelinating diseases, such as multiple sclerosis, illustrate well the importance of the process. In this review, we focus on the positive and negative interactions between oligodendrocytes, astrocytes, and microglia during developmental myelination and remyelination. Even though many lines of evidence support a crucial role for glia crosstalk during these processes, the nature of such interactions is often neglected when designing therapeutics for repair of demyelinated lesions. Understanding the cellular and molecular mechanisms underlying glial cell communication and how they influence oligodendrocyte differentiation and myelination is fundamental to uncover novel therapeutic strategies for myelin repair.

Keywords: oligodendrocyte, astrocyte, microglia, multiple sclerosis (MS), experimental autoimmune encephalomyelitis (EAE), myelination, demyelination, remyelination

\section{INTRODUCTION}

Glial cells, neuroglia, or simply glia, in the adult mammalian central nervous system (CNS) comprise astrocytes, oligodendrocytes, and microglia. Collectively, they are by far the most abundant cells in the nervous system. The term glia, derived from the Greek word meaning glue, reflects the nineteenth-century view of Rudolph Virchow that these cells had the function to hold the nervous system together (Virchow, 1856). Today, we know that glia play many other roles, such as modulation of homeostatic functions, myelination, synaptic function, nerve signal propagation and responses to neural injury (for extended information please see reviews Herculano-Houzel, 2014; Zuchero and Barres, 2015).

Astrocytes have star-shape morphology and are the most abundant CNS glial cell type. They play essential functions in blood brain barrier maintenance, neuronal survival, and in synapse formation, strength, and turnover (Barres, 2008). First characterized by del Río-Hortega (1928), oligodendrocytes are the myelinating glia of the CNS (Nave and Werner, 2014) and their myelin sheaths enwrap axons to allow fast saltatory conduction of action potentials. They also provide axonal metabolic support (Funfschilling et al., 2012) and contribute for neuroplasticity (Mckenzie et al., 2014). While oligodendrocytes and astrocytes originate from a common lineage of neural progenitor cells within the neuroectoderm, microglia are the main innate immune cells of the CNS and arise from hematopoietic stem cells in the yolk sac during early embryogenesis that populate the central nervous system. Being ontogenetically different from other tissue-macrophages they have longevity and capacity for self-renewal (Chan et al., 2007; Prinz and Priller, 2014). 
The roles of glial cells in health and in disease have been partially neglected because many basic aspects of their physiology and pathophysiology are still not completely understood. However, it is becoming more evident that gliaglia crosstalk plays several important roles in brain function during development and disease. This review discusses how in their active interplay, astrocytes and microglia can modulate oligodendrocyte homeostasis during myelination, demyelination and remyelination.

\section{GLIAL CELL INTERACTIONS IN CNS (RE)MYELINATION AND DEMYELINATION \\ Oligodendrocyte Differentiation in Health and Disease \\ Oligodendrocyte Differentiation in Developmental Myelination}

In the CNS, myelination is carried by oligodendrocytes. The myelin sheath is a modified and extended glial plasma membrane that enwraps around the axons enabling fast saltatory nerve conduction and axon integrity (Nave and Werner, 2014). Demyelination, the process or state resulting from the loss or destruction of myelin, is a hallmark of numerous diseases, such as multiple sclerosis (MS), contusion type spinal cord injury (SCI), and stroke. Oligodendrocytes derive from oligodendrocyte progenitor cells (OPC), which hold the capacity to proliferate, migrate, and differentiate into myelinating oligodendrocytes. Demyelination is often followed by remyelination, the default spontaneous process by which new OPC are recruited to differentiate into myelinating oligodendrocytes and the myelin sheaths are restored to axons, protecting them from degeneration. Ideally, remyelination should recapitulate developmental myelination. However, the inflammatory and activated milieu surrounding the demyelinated lesions compromises and limits the efficacy of the remyelination process (Franklin and Goldman, 2015).

OPC are highly proliferative, motile and bipolar cells expressing high levels of the gangliosides recognized by the A2B5 antibody, the receptor of PDGF alpha (PDGF $\alpha \mathrm{R})$, and the NG2 proteoglycan. OPC specification and differentiation is regulated by transcription factors such as Olig1, Olig2, Mash, Myt1, Nkx2.2, and Sox10 and their differentiation along the oligodendroglial lineage, can be regulated by molecules such as IGF-1, FGF2, CNTF, and thyroid hormone T3 (see reviews from Zuchero and Barres, 2013; Mitew et al., 2014; Figure 1).

There are at least two identified sources of OPC in the adult brain: the progenitors from the subventricular zone (SVZ) (Menn et al., 2006) and the NG2 and PDGF $\alpha$ R positive OPC, believed to be homogeneously distributed within the CNS (Nishiyama et al., 1996; Watanabe et al., 2002; Rivers et al., 2008; Richardson et al., 2011). These cells account for $5-8 \%$ of all cells in the CNS (Levine et al., 2001) and exist throughout regions such as the optic nerve (Shi et al., 1998), motor cortex, corpus callosum (Clarke et al., 2012), and cerebellum (Levine et al., 1993), providing a substantial source of new oligodendrocytes and, thus, a potential reservoir for remyelination. Adult OPC are oligodendrocyte precursors with restricted lineage potential, generating myelinating oligodendrocytes, but not astrocytes or neurons, not even during disease (Kang et al., 2010). Interestingly, these cells are constantly proliferating in the CNS to maintain their homeostatic cell density (Hughes et al., 2013), though at slower rate than during development or injury (Shi et al., 1998; McTigue et al., 2001). Oligodendrocytes are generated continuously in the healthy adult brain. In human brain, although the oligodendrocyte turnover is very stable, with an annual change of $0.3 \%$ (Yeung et al., 2014), increasing evidence shows that myelin is produced and remodeled throughout life, not just during childhood and adolescence. Actually, it was shown that inhibiting the formation of new oligodendrocytes during adulthood, without compromising preexisting oligodendrocytes and myelin, prevented mice from learning new motor skills (Mckenzie et al., 2014), suggesting that the formation of new myelinating oligodendrocytes during adult life is an important mechanism for neuroplasticity. Moreover, Birey and colleagues describe a new role for NG2 glial cells in the regulation of CNS homeostasis, other than their myelinating potential. The depletion of NG2 glia in the prefrontal cortex of the adult mouse brain caused deficits in excitatory glutamatergic neurotransmission and astrocytic extracellular glutamate uptake and induced depressive-like behaviors (Birey et al., 2015). Finally, Hughes and colleagues showed that NG2 positive cells also participate in the formation and resolution of the glial scar, suggesting that these progenitor cells are also able to detect CNS injury and promote tissue repair (Hughes et al., 2013).

OPC differentiation into a myelinating oligodendrocyte is characterized by a rapid increase in morphological complexity followed by expansion of uncompacted myelin membrane. Such profound morphological changes demand dynamic cytoskeleton rearrangements of microtubules and actomyosin (F-actin) (Bauer et al., 2009; Snaidero and Simons, 2014). In the past years, we and others have contributed to the identification and understanding of the role of regulatory proteins that govern the cytoskeletal function during developmental myelination in the CNS, namely the $\beta 1$ integrin, the Rho GTPases Racl and Cdc42 and the extracellular matrix (ECM) proteins fibronectin and laminin (Relvas et al., 2001; Benninger et al., 2006; Thurnherr et al., 2006; Lourenco et al., 2016).

\section{Oligodendrocyte Differentiation after Myelin Damage}

Following injury, and myelin damage, NG2/PDGF $\alpha$ R-expressing adult progenitors differentiate into oligodendrocytes capable of remyelinating axons (Zawadzka et al., 2010) and restoring nearly normal nerve conduction. However, over the course of MS changes in the microenvironment of the injured nervous system cause OPC to gradually loose the ability to respond to myelin damage limiting their remyelination capacity (Kipp et al., 2012). It is thought that for remyelination to occur, OPC need to be "activated." These progenitor cells become responsive to mitogens, growth factors, chemokines and cytokines, which enhance their proliferation and mobilization to the demyelinated area, and increase the expression of genes associated with oligodendroglial differentiation (Redwine and Armstrong, 1998; Di Bello et al., 


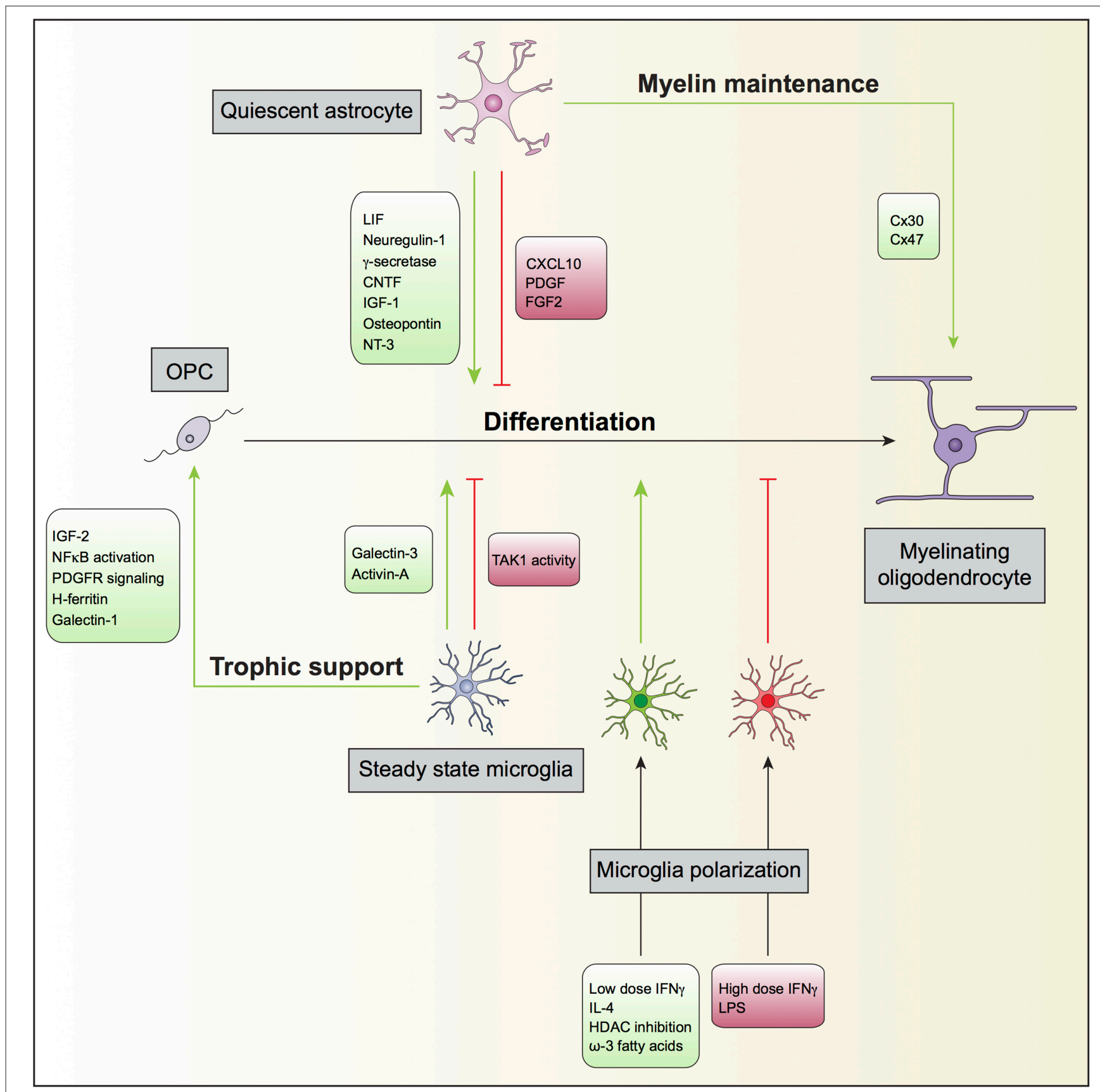

FIGURE 1 | Oligodendrocyte, astrocyte, and microglia crosstalk during developmental myelination. In the non-diseased or non-insulted CNS, both quiescent astrocytes and steady state microglia may potentiate (green) or prevent (red) the differentiation of oligodendrocyte progenitor cells (OPC) into mature myelinating oligodendrocytes. Quiescent astrocytes can also support myelin maintenance, which will consequently enhance myelin production by myelinating oligodendrocytes. Steady state microglia might additionally contribute to oligodendrocyte differentiation by providing trophic support to OPC. Furthermore, microglia can modulate OPC differentiation directly after polarization by exogenous ligands. For instance, while the inflammagen LPS polarize microglia to prevent (red), the anti-inflammatory cytokine IL-4 polarize microglia to promote (green) OPC differentiation.

1999; Fancy et al., 2004; Moyon et al., 2015). Experimental evidence strongly suggests that in MS, OPC depletion is not a limiting step for remyelination but rather the inhibition of OPC recruitment and differentiation into myelinating oligodendrocytes (Boyd et al., 2013). In fact, a quantitative analysis of oligodendrocytes in MS lesions showed that only $30 \%$ of the lesions were devoid of OPCs, while the other $70 \%$ contain an increased number of OPC that were unable to differentiate and remyelinate axons (Lucchinetti et al., 1999). A recent study reported that rodent adult OPC have 
a transcriptome more similar to oligodendrocytes than to neonatal OPC. However, in demyelinating conditions, adult OPC are activated and revert their phenotype to a more neonatal OPC, and produce the cytokine IL- $1 \beta$ and chemokine CCL2 that enhance OPC mobilization and promote their repopulation in demyelinating areas (Moyon et al., 2015). This study shows that OPC can modulate neuroinflammation and promote regeneration and are not simple target cells.

\section{Oligodendrocyte Injury: Cause or Consequence of Inflammation?}

MS is an inflammatory disorder causing CNS demyelination and axonal injury. Although its etiology remains elusive, many reports associate autoimmunity, genetic predisposition, and environmental factors as triggers for MS pathogenesis. This autoimmune response is thought to be mediated by myelinspecific $\mathrm{CD}^{+} \mathrm{T}$ cells that initiate a series of neuroinflammatory events conjugated with those of either innate and adaptive infiltrating immune and CNS resident cells. This ultimately leads to the attack of myelin-producing oligodendrocytes, culminating in demyelination followed by axonal damage (Bauer et al., 2009; Nicol et al., 2015). In alternative to this long- favored hypothesis it has been proposed that the disease process could be triggered by events primarily occurring within the CNS. For example, it has been shown that primary oligodendroglial dystrophy in type III and IV lesions was followed by subsequent inflammation (Lucchinetti et al., 2000). Based on observations of lesions of patients with relapsing and remitting multiple sclerosis (RRMS) with extensive oligodendrocyte apoptosis, microglial activation, and few or no lymphocytes or myelin phagocytes (Barnett and Prineas, 2004), it has also been suggested a novel mechanism of new MS lesion formation initiation. This hypothesis is in agreement with the identification of extracellular myelin in MS leptomeninges and perivascular spaces, suggesting primary myelin trafficking from the CNS to the secondary lymphoid organs for further antigen presentation to immune cells to mount the autoimmune neuroinflammatory response (Fabriek et al., 2005; Kooi et al., 2009). Recently, using a transgenic mouse model for inducible depletion of adult oligodendrocytes it was verified that oligodendrocyte loss is followed by infiltration of $\mathrm{CD}^{+} \mathrm{T}$ cells into the CNS leading to a secondary, fatal demyelinating disease. Focal lesions with $\mathrm{T}$ cell infiltration and macrophage/microglia inflammation characterized this late onset demyelination. Moreover, myelin-specific $\mathrm{T}$ cells were identified in peripheral lymphoid organs and after isolation and in vitro activation could, by adoptive transfer, induce mild neurological symptoms, and inflammatory white matter lesions in the recipient animals (Traka et al., 2016). This study clearly raises the concept of autoimmunity to another level of complexity that requires a deeper understanding. Altogether, these data suggest that CNS demyelination is caused by a multitude of complex pathophysiologic mechanisms with several possible scenarios and cellular players. Therefore, it is extremely relevant to address when and how these interactions take place in de(re)myelinating conditions.

\section{Role of Astrocytes in (re)Myelination Astrocyte Phenotypes}

Astrocytes (Andriezen, 1893) are originated from neural embryonic progenitor cells that line the lumen of the embryonic neural tube. However, they can be formed indirectly via radial glia, which in addition to function as scaffolding for newborn neuron migration, can serve as progenitor cells giving rise to astrocytes (Choi, 1981; Voigt, 1989; Kessaris et al., 2008). Astrocytic heterogeneity is far more complex than initially imagined and there is no complete consensus in their categorization. However, the classification of astrocytes by Ramón y Cajal into protoplasmic and fibrous astrocytes (Ramón Y Cajal, 1909) based on differences in their morphology, antigenic phenotype, location and function, is still valid and useful. Type 1 astrocytes (protoplasmic astrocytes) are localized in the gray matter and ensheath synapses and blood vessels to promote synapse and blood brain barrier functions, respectively. Type 2 astrocytes (fibrous astrocytes) are localized in the white matter and contact the nodes of Ranvier and the blood vessels (Barres, 2008; Sofroniew and Vinters, 2010). In addition, astrocytes can also be diverse in their ability to react in response to CNS insults. Astrocytes range from inactive or quiescent to active and reactive. Quiescent astrocytes exist in the normal resting CNS tissue. Upon injury or insult, astrocytes become activated by various mechanisms that result in mild astrogliosis. Reactive astrocytes are closer to the injury site and are responsible for the glial scar formation (Nash et al., 2011a). Astrocyte reactivity seems to influence myelination differently and it will be discussed in the next sections.

\section{Astrocyte-Derived Promoters of Oligodendrocyte Proliferation, Differentiation, and Myelination}

The processes by which astrocytes facilitate each step of myelination, including OPC proliferation, differentiation, initial oligodendrocyte-axon contact, and myelination, have been addressed in several studies (Figure 1). It is generally accepted that astrocytes support oligodendrocyte function. The first evidence of interplay between astrocytes and oligodendrocytes and its impact on myelination dates back to the middle 80's, when type 1 astrocytes were identified to expand O-2A progenitors from neonatal rat optic nerve. Such expansion was found to be mediated by unidentified soluble growth factors (Noble and Murray, 1984), later identified as platelet-derived growth factor (PDGF) (Noble et al., 1988; Richardson et al., 1988) and basic fibroblast growth factor (FGF2) (Bogler et al., 1990). PDGF and FGF2 are both potent mitogens for OPCs and inhibit premature oligodendrocyte differentiation.

Other soluble factors secreted by astrocytes have been implicated in enhancing myelination. Bhat and Pfeiffer observed that extracts from cultures enriched in astrocytes stimulated oligodendrocyte differentiation (Bhat and Pfeiffer, 1986), thus supporting the concept of a positive effect of astrocytes in myelination. In agreement with these findings, Gard and co-workers identified leukemia inhibitory factor-like protein (LIF) in conditioned medium produced by astrocytes that promoted oligodendrocyte survival and maintained them in a mature myelinogenic state (Gard et al., 1995). Ishibashi 
and colleagues also showed that astrocyte release of LIF in response to electrical activity in axons promoted oligodendrocyte myelination (Ishibashi et al., 2006). Other examples are neuregulin-1 (Taveggia et al., 2008), gamma-secretase (Watkins et al., 2008), ciliary neurotrophic factor (CNTF) (Stankoff et al., 2002), insulin-like growth factor 1 (IGF-1) (Ye et al., 2004; Zeger et al., 2007), osteopontin (Selvaraju et al., 2004), and neurotrophin-3 (NT3) (Kumar et al., 2007). Cocultures of astrocytes and oligodendrocytes revealed that astrocyte proximity, in a contact-independent manner, induced profound changes in the levels of oligodendrocyte gene expression, in particular the expression of several myelin-related and cytokine receptors genes (Iacobas and Iacobas, 2010). Sorensen and colleagues showed that in cultures generated from rat embryonic spinal cord, neurosphere-derived astrocytes promoted myelination of CNS axons (Sorensen et al., 2008). Finally, Nash and colleagues found correlation of astrocyte phenotypes with their ability to support myelination. Activated astrocytes by CNTF increased myelination, while quiescent astrocytes induced by tenascin C through CXCL10 resulted in less myelinated fibers (Nash et al., 2011b). The analysis of postmortem brains of neonatal brain injury also revealed that the presence of activated STAT3 signaling in reactive astrocytes prevented the impairment of oligodendrocyte maturation (Nobuta et al., 2012).

Physical contact with astrocytes can also facilitate the maturation of oligodendrocytes (Sakurai et al., 1998). Astrocytes were found to promote adult mouse oligodendrocyte survival through a cell-contact dependent mechanism involving the interaction of $\alpha 6 \beta 1$ integrin on oligodendrocytes with laminin on astrocytes (Corley et al., 2001).

Moreover, myelin homeostasis in the CNS is dependent on the proper function of oligodendrocyte and astrocyte connexins (Orthmann-Murphy et al., 2008; Lutz et al., 2009). Astrocytes express connexin $43(\mathrm{Cx} 43)$ and $\mathrm{Cx} 30$ and may couple to other astrocytes by homotypic gap junction composed of $\mathrm{Cx} 43-\mathrm{Cx} 43$ or Cx30-Cx30 while oligodendrocyte express Cx32 and Cx47 and also couple to one another using $\mathrm{Cx} 32-\mathrm{Cx} 32$ or $\mathrm{Cx} 47-\mathrm{Cx} 47$ gap junctions. Astrocytes and oligodendrocytes also establish heterotypic gap junctions composed of $\mathrm{Cx} 47-\mathrm{Cx} 43$ or, to a lesser extent, Cx32-Cx30 (Orthmann-Murphy et al., 2008). The elimination of gap junctions coupling oligodendrocytes and astrocytes in mice through oligodendrocytic $\mathrm{Cx} 47$ and astrocytic Cx30 delayed myelination, revealing a role for connexins and glial physical connection in myelin maintenance (Tress et al., 2012). The observation of a unidirectional flow through gap junctions, whereby cytosolic contents originating from astrocytes are preferentially transported to oligodendrocytes suggests that these cells are metabolically supported by astrocytes (Robinson et al., 1993). It was also proposed that astrocytes might buffer the concentration of potassium ions that accumulate in the white matter during neurotransmission in oligodendrocytes through gap junctions (Nagy and Rash, 2000).

In addition to promoting oligodendrocyte survival and differentiation, astrocytes also affect other aspects of oligodendrocyte biology. Astrocytes promote adult human oligodendrocyte process extension through FGF2 in combination with the ECM proteins fibronectin and laminin (Oh and Yong, 1996), in a protein kinase C (PKC)-dependent manner (Oh et al., 1997).

\section{Astrocyte-Derived Promoters of Remyelination}

In remyelination models using chemical demyelination, Franklin and colleagues showed that in vivo transplantation of type 1 astrocytes potentiated oligodendrocyte remyelination and increased the thickness of myelin sheaths (Franklin et al., 1991). In cuprizone-induced demyelination, the expression of TNFR2 in astrocytes resulted in the autocrine expression of CXCL12, which acted at its receptor CXCR4 on OPC, inducing their proliferation and differentiation, therefore enabling remyelination (Patel et al., 2012; Figure 2). In addition, CNTF was identified within activated/reactive astrocytes in and around spinal cord remyelinating lesions, and regulated FGF-2 production in astrocytes during early remyelination, suggesting CNTF as an important cytokine in demyelinating diseases (Albrecht et al., 2003). Skripuletz and co-workers showed that astrocyte ablation during cuprizone-induced demyelination did not prevent myelin damage but rather inhibited the removal of the myelin debris and delayed remyelination (Skripuletz et al., 2013). Interestingly, two studies using different models of demyelination of spinal cord white matter observed that the absence of astrocytes in the lesion area decreased the oligodendrocyte-mediated remyelination and increased remyelination mediated by Schwann cells (Talbott et al., 2005; Monteiro De Castro et al., 2015). Altogether, these results suggest that the astrocyte free regions of the lesion either contained inhibitory signals preventing terminal differentiation of OPC or lack appropriate signals necessary for OPC to undergo terminal differentiation.

\section{Astrocyte-Derived Inhibitors of (re)Myelination}

Astrocytes have been initially described to have detrimental effects on oligodendrocyte differentiation, in particular those within the glial scar. Astrocytes within the glial scar inhibited regeneration and impacted negatively on remyelination (Fawcett and Asher, 1999; Silver and Miller, 2004). In vitro studies showed that type 1 astrocytes inhibited myelination of dorsal root ganglion axons by adult oligodendrocytes (Rosen et al., 1989). Astrocytes also secrete factors implicated in the inhibition of myelination and remyelination. Besides the above mentioned PDGF and FGF2 (Noble et al., 1988; Richardson et al., 1988; Bogler et al., 1990), which promote OPC proliferation and inhibit premature differentiation, others such as tenascin C (Nash et al., 2011b), bone morphogenetic proteins (BMP)2/4 (Wang et al., 2011), and hyaluronan (Sloane et al., 2010) have also been described. Hyaluronan is a glicosaminoglican (GAG) that interacts with CD44, a receptor present in OPC. This interaction impairs remyelination after lysolecithin-induced white matter demyelination because OPC do not differentiate into myelinforming cells in demyelinating lesions where hyaluronan is present. Paralleling these findings, OPC differentiation was also blocked by treating OPC cultures with hyaluronan (Back et al., 2005). Astrocyte-derived endothelin-1 (ET-1) was identified to be a negative regulator of OPC differentiation and remyelination by promoting Jagged1 expression that activates Notch on OPC 


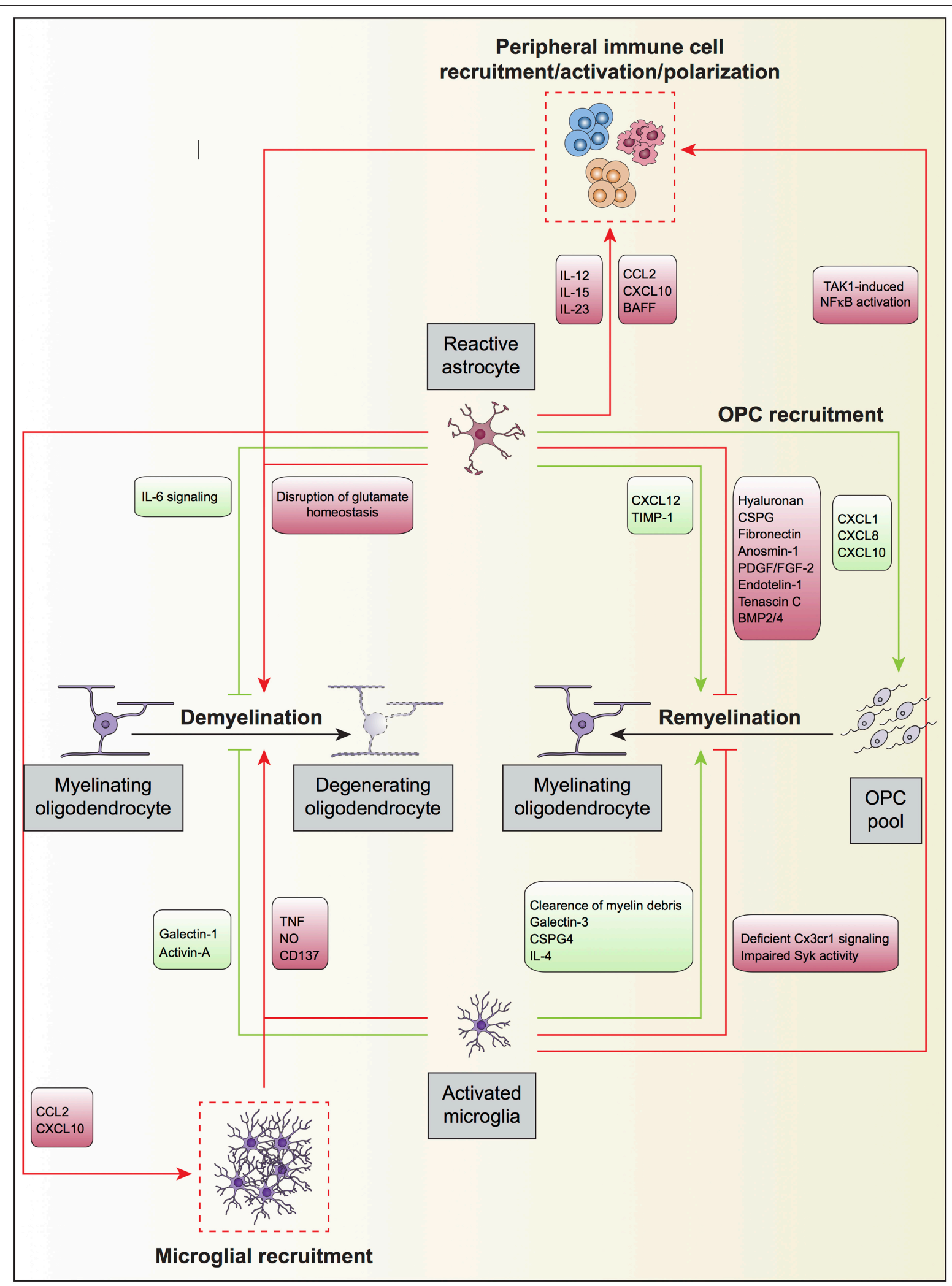

FIGURE 2 | Oligodendrocyte, astrocyte, and microglia crosstalk during demyelination and remyelination. Upon an insult to the CNS parenchyma or in neurodegenerative diseases, mature myelinating oligodendrocytes degenerate and eventually die, a processes termed active demyelination. Reactive astrocytes and activated microglia directly participate in this process displaying both detrimental (red) and beneficial (green) roles. Astrocytes may also modulate the recruitment of 


\section{FIGURE 2 | Continued}

peripheral immune cells by secreting different set of cytokines and chemokines, which will further promote the degeneration of myelinating oligodendrocytes. Furthermore, astrocytes secrete the chemokines CCL2 and CXCL10 to recruit overactive microglia, which may further increase oligodendrocyte loss. Microglial TAK1 signaling is also involved in the recruitment of peripheral immune cells to regulate active demyelination. On the other hand, astrocytes and microglia promote remyelination after myelin damage by the generation of oligodendrocytes from the OPC pool in the neuronal parenchyma. During remyelination, and as occurs for active demyelination, reactive astrocytes, and activated microglia can promote (green) or impede (red) the process. Astrocyte can further influence remyelination by secreting the chemokines CXCL1, CXCL8, and CXCL10 to recruit OPC to demyelinated zones where they can differentiate into mature oligodendrocytes.

(Hammond et al., 2014). Blakemore and colleagues showed that remyelination was more efficient after transplantation of neonatal OPC into an astrocyte-free area of demyelination than into an area with established astrocytes (Blakemore et al., 2003). This contrasts with previous work from Franklin and colleagues, in which they showed a positive effect of astrocytes in remyelination, using a more acute model of demyelination (Franklin et al., 1991) (Figure 2). Finally, a recent report demonstrates that preventing astrocytic scar formation in SCI significantly reduces stimulation of axon regrowth (Anderson et al., 2016). Although no information concerning myelin was provided, this study supports a positive role for astrocytes during regeneration.

Overall, these studies suggest that the outcome of glial interactions in myelination is affected by the surrounding microenvironment, emphasizing that the activation state of astrocytes likely determines their permissive or inhibitory influence on oligodendrocyte development. Besides the different possibilities of astrocyte phenotypes, it should also be considered the distance of these populations to the lesion site, as relatively small changes in the responsive milieu may have different impacts on oligodendrocyte behavior. Nash and colleagues hypothesized that while astrocytes more distal to injury are activated cells that contribute in a greater extent to regeneration via the secretion of growth factors and cytokines, astrocytes in closer proximity to the lesion site are more reactive and may hinder the remyelination process (Nash et al., 2011a).

\section{Astrocytes in Demyelinating Diseases: Focus on MS and EAE}

Astrogliosis is one of MS pathological hallmarks. Astrocytes play an active role in both promoting demyelination and impairing remyelination by regulating peripheral immune cell trafficking, modulating BBB integrity, and being a source of chemokines and cytokines with pleiotropic functions (Figure 2).

\section{Astrocytes and BBB Function}

$\mathrm{BBB}$ dysfunction is also a hallmark of MS progression. Astrocyte activation and loss of their end-feet around small blood vessels represent an early event in lesion development linked to BBB disruption in EAE (Correale and Farez, 2015). Astrocyte activation increases HIF-1, up-regulating VEGF-A expression, which induces the down-regulation of claudin5 and occludin, important proteins that compose the tight junctions of endothelial cells, leading to BBB injury (Argaw et al., 2006, 2009, 2012). Gimenez and colleagues demonstrated that vascular adhesion molecule-1 (VCAM-1) expression, specifically by astrocytes, is crucial for T cell invasion of the CNS parenchyma in EAE (Gimenez et al., 2004). They also demonstrated that the VCAM-1 expression by astrocytes is dependent on TNFR1 expression (Gimenez et al., 2004). Still, it was observed in an in vitro BBB model (Megard et al., 2002), that IL-1 $\beta$ secretion by astrocytes is pivotal in mediating TNF-induced paracellular transport in endothelial cells (Didier et al., 2003).

\section{Astrocytes and Chemokine Production/Immune Cell Recruitment}

Astrocytes secrete a plethora of chemokines and cytokines (Dong and Benveniste, 2001) that regulate different immune events during MS progression. Astrocytes were found to be the main source of the chemokine CCL2 in EAE (Ransohoff et al., 1993). This molecule is an essential chemoattractant for monocytes and $\mathrm{T}$ cells and exerts a key role in the onset of MS (Huang et al., 2001). Curiously, Toft-Hansen and colleagues, using transgenic mice expressing herpes simplex virus-derived thymidine kinase under the control of a glial fibrillary acidic protein promoter, investigated whether inhibition of reactive astrocytosis influences established EAE. In this experimental setting, the inhibition of reactive astrocytosis blocked the infiltration of $\mathrm{T}$ cells while the infiltration of monocytes were increased. It was also observed that the mRNA expression of CCL2 was upregulated, and of CXL10 downregulated, dissociating the reactive astrocytosis (GFAP expression) from CCL2 mRNA expression (Toft-Hansen et al., 2011). To corroborate the role of pro-inflammatory chemokines produced by astrocytes in MS pathology, Brambilla and colleagues blocked astroglial NF- $\kappa \mathrm{B}$ activation in dominant negative transgenic mice (glial fibrillary acidic protein- $\mathrm{I} \kappa \mathrm{B} \alpha$ ). A clear reduction of chemokine gene expression was observed in these animals, which attenuated disease severity and improved functional recovery following EAE (Brambilla et al., 2009). In the same animal model, the authors also demonstrated a reduction of peripheral immune cell infiltration into the CNS at the chronic phase of EAE (Brambilla et al., 2014).

There is evidence that cytokines produced by astrocytes, such as IL-12, IL-23, and IL-15, regulate the myelin-specific autoreactive response of effector $\mathrm{T}$ cells, namely by inducing the differentiation of $\mathrm{CD}^{+} \mathrm{T}$ cells in a pro-inflammatory phenotype such as Th1 or Th17 and also the cytotoxic activity of $\mathrm{CD}^{+}$ $\mathrm{T}$ cells (Correale and Farez, 2015). Reducing astroglial NF- $\kappa \mathrm{B}$ activation specifically attenuated the ability of $\mathrm{T}$ cells to produce pro-inflammatory cytokines during acute disease, suggesting that pro-inflammatory cytokines produced by astrocytes are important to regulate the ability of $\mathrm{T}$ cells to produce proinflammatory mediators (Brambilla et al., 2014). Th17 cells are major mediators of EAE progression and mice lacking IL-17 display less severe inflammation, indicating that IL-17-mediated 
signaling plays a critical role in the effector phase of EAE (Komiyama et al., 2006). The major function described for these cells is the coordination of local tissue inflammation through upregulation of pro-inflammatory cytokines and chemokines (Jovanovic et al., 1998). IL-17 acts through an heteromeric receptor complex, consisting of IL-17R (IL-17RA) and IL-17RC, which is expressed by a variety of cells including astrocytes ( $\mathrm{Gu}$ et al., 2013). It was described that Act1 is an adaptor protein essential for the signaling mediated by IL-17 receptor (Chang et al., 2006) and induction of NF- $\kappa$ B activation (Li et al., 2000). Kang and colleagues demonstrated that the deletion of Act1 in the neuroectodermal lineage in mice results in attenuated EAE severity. Act1-deficient astrocytes showed impaired IL-17mediated inflammatory gene induction (Kang et al., 2010), which was further corroborated by Yan and colleagues that knocked down Act1 expression specifically on astrocytes and effectively prevented EAE progression (Yan et al., 2012).

Astrocytes also regulate $\mathrm{B}$ cell activation by producing $\mathrm{B}$ cellactivating factor (BAFF), a cytokine that belongs to the TNF family. During MS, the production of this factor is increased in astrocytes in MS lesions (Krumbholz et al., 2005) and such increase may promote survival, expansion and activation of $\mathrm{B}$ cells during MS progression.

It was demonstrated that hypertrophic astrocytes produce the chemokines CCL2 and CXCL10 that activate microglia in the rim of the secondary progressive multiple sclerosis lesions (SPMS) with ongoing demyelination (Tanuma et al., 2006). As at this stage, leucocyte infiltration is at a minimum or absent, glial cells and glial-glial interaction might be the culprits sustaining demyelination. Using dominant-negative transgenic inhibition of astroglial NF- $\kappa \mathrm{B}$, it was observed that the number of total and activated microglial cells is reduced in chronic EAE. This resulted in a reduction of the overall inflammatory response and improved neurological function in GFAP-I $\kappa \mathrm{B} \alpha-\mathrm{dn}$ mice (Brambilla et al., 2014).

\section{Astrocytes Acting on Demyelination}

In inflammatory and/or demyelinating conditions, astrocytes proliferate and may form glial scars composed of a dense network of hypertrophic cells. These reactive astrocytes have pronounced changes in the expression levels of adhesion molecules, antigen presentation molecules, cytokines, growth factors, receptors, enzymes, and protease inhibitors that modify the composition of the ECM.

Reactive astrocytes at the edge of active MS lesions express chemoattractant molecules for OPC, including CXCL8, CXCL1, and CXCL10, inducing their migration toward the demyelinated plaque, which might be important for remyelination (Omari et al., 2005).

It is well-recognized that the glial scar formation is crucial for helping restore blood brain barrier (BBB) integrity. However, in demyelinating conditions it also poses a physical barrier preventing OPC entry into the demyelinated area for interaction with denuded neurons (Fawcett and Asher, 1999; Silver and Miller, 2004; Nair et al., 2008; Wang et al., 2011). In the EAE model, it was observed that OPC could migrate toward the demyelinated lesion but were stuck at its margins, unable to penetrate the lesion site (Bannerman et al., 2007a; Williams et al., 2007). The glial scar not only represents a physical barrier but also a biochemical obstacle for remyelination. Astrocytes are capable of modifying the ECM in MS by secreting different components, which can directly affect remyelination in MS lesions (Clemente et al., 2013). For instance, astrocytes can produce a high molecular weight form of hyaluronan found to accumulate in chronic MS or EAE demyelinated lesions (Back et al., 2005). Moreover, chondroitin sulfate proteoglycans (CSPG) are produced by reactive astrocytes at the border of demyelinating areas (Lau et al., 2012). This ECM component inhibits OPC process outgrowth, differentiation and adhesion and impairs remyelination. CSPG-mediated remyelination impairment is dependent on protein tyrosine phosphatase sigma (PTPÏČ) and Rho-associated kinase (ROCK) activation (Pendleton et al., 2013). Inhibition of ROCK or RNAi-mediated down-regulation of PTPÏČ increases oligodendrocyte process outgrowth and myelination during exposure to CSPGs (Pendleton et al., 2013). Fibronectin is a glycoprotein of the ECM that inhibits the outgrowth of oligodendrocyte processes and myelin sheath formation (Siskova et al., 2009). Astrocytes secrete fibronectin in chronic MS lesions (Stoffels et al., 2013, 2015), stimulating OPC proliferation (Stoffels et al., 2015), but impairing oligodendrocyte differentiation and remyelination (Stoffels et al., 2013). Anosmin1 is another astrocytic-secreted ECM associated glycoprotein that is deregulated in MS. Anosmin-1 is present at the core of chronic active and chronic inactive plaques (areas where remyelination is compromised). The presence of this component impedes OPC colonization of MS lesions and oligodendrocyte differentiation (Clemente et al., 2013). Reactive astrocytes over-secrete FGF2 during EAE (Messersmith et al., 2000) and in MS plaques (Holley et al., 2003). This growth factor promotes OPC survival and proliferation but prevents their differentiation into mature oligodendrocyte (Goddard et al., 1999), impairing remyelination. Endothelin-1 (ET-1) is a secreted signaling peptide also highly expressed by reactive astrocytes in demyelinated lesions in MS (Hammond et al., 2014). This peptide reduces the rate of remyelination by acting indirectly in OPC and in an autocrine manner on astrocytes through endothelin-B receptor activation (Hammond et al., 2015).

Excitotoxic injury to the oligodendroglial lineage is another way by which astrocytes may impair remyelination during EAE. In normal conditions, astrocytes regulate glutamatergic neurotransmission by taking up extracellular glutamate from the CNS extracellular milieu and converting it into L-glutamine via activity of glutamine synthetase. During EAE, the expression of the glutamate transporters, GLAST, and GLT-1 (Ohgoh et al., 2002), glutamine synthetase and glutamate dehydrogenase (Hardin-Pouzet et al., 1997) are diminished in astrocytes, driving glutamate accumulation in the extracellular milieu, contributing to oligodendrocyte excitotoxic injury via activation of calciumpermeable AMPA receptors (Bannerman et al., 2007b).

Astrocyte-induced inflammation is harmful to myelin homeostasis and impairs remyelination. Inhibition of astroglial $\mathrm{NF}-\kappa \mathrm{B}$ during EAE, increases myelin preservation, improving myelin compaction, and remyelination (Brambilla et al., 2014). On the other hand, deletion of gp130, the signal-transducing 
receptor for cytokines of the IL-6 family, specifically in astrocytes during EAE leads to more severe disease. The loss of astrocytic gp130 expression resulted in apoptosis of astrocytes in inflammatory lesions, larger areas of demyelination, and increased numbers of $\mathrm{CD}^{+}{ }^{+} \mathrm{T}$ cells within the CNS parenchyma (Haroon et al., 2011), demonstrating that the IL-6 signaling in astrocytes is important to reduce demyelination in EAE.

Another important aspect in glial-glial interaction during demyelination is the gap junction formation between astrocytes and oligodendrocytes (Lutz et al., 2009). During acute EAE, both $\mathrm{Cx} 47$ and $\mathrm{Cx} 32$ are severely reduced within and around lesions. The $\mathrm{Cx} 47$ protein was relocated intracellularly in oligodendrocytes, and its redistribution coincided with the loss of Cx43 in astrocytes (Markoullis et al., 2012). Moreover, there is loss of oligodendrocyte-oligodendrocyte and oligodendrocyteastrocyte gap junctions and an increase in astrocyte-astrocyte gap junctions in gray matter MS lesions, suggesting that oligodendrocyte dissociation from reactive astrocytes may account for remyelination failure and disease progression in EAE (Markoullis et al., 2014).

On the other hand, metalloproteinase inhibitors expressed by astrocytes can play positive roles in oligodendrocyte response to injury. One known example is the tissue inhibitor of metalloproteinase (TIMP-1). In the EAE model, TIMP-1 is increased in reactive astrocytes, which regulates the secretion of matrix metalloproteinases from these cells (Nygardas and Hinkkanen, 2002). Moreover, TIMP-1 deficient mice exhibit poorer myelin repair in the EAE model (Crocker et al., 2006), have a specific deficit of NG2 positive OPC, and oligodendrogenesis is significantly impaired, correlating with dramatically reduced numbers of white matter astrocytes in the developing CNS (Moore et al., 2011).

\section{Modulation of (re)Myelination and Demyelination by Microglia}

Microglia constitute the myeloid resident population of the CNS, representing around $10 \%$ of the total glial cells within the nervous tissue (Soulet and Rivest, 2008). Microglia are critically involved in the scavenging of dying cells, pathogens, and molecules that engage pattern recognition receptors. As the major component of the immune effector system of the CNS at steady-state conditions, surveillant microglia are usually claimed to act as sensors of pathologic events (Hanisch and Kettenmann, 2007). Microglial activation has been described extensively in autoimmune diseases such as multiple sclerosis in humans and in the EAE mouse MS model. In these pathological contexts, microglia can produce and release neurotoxic (reactive oxygen and nitrogen species and glutamate) or neurotrophic molecules, pro and anti-inflammatory cytokines or chemokines, and present self-antigens to effector immune cells. Pathological evidence indicates that the remyelination onset in fresh lesions of brain and spinal cord of patients with MS occurs in acute, active lesions, which are characterized by a robust inflammatory response (Prineas et al., 1989). Following injury, different inflammatory molecules such as cytokines and chemokines are secreted and released by glial cells, inclusive microglia, in the surrounding milieu. In this scenario, microglia become activated, expand, migrate, and accumulate within the damaged area of the neuronal parenchyma, playing both beneficial and detrimental roles during myelin damage and repair (Figure 2).

\section{Beneficial vs. Detrimental Roles of Microglia in (re)Myelination and Demyelination}

Although the literature relating microglia to myelination is not very extensive, several reports show that in homeostatic conditions microglia may also promote OPC survival and differentiation (Figure 1). Early studies using microglia and oligodendrocyte co-cultures showed that the former stimulated the synthesis of sulfatide, a myelin-specific galactolipid, as well as the expression of the myelin-specific proteins MBP and proteolipid protein (PLP) in oligodendrocytes, suggesting a positive role for microglia in myelination (Hamilton and Rome, 1994). In line with this, conditioned medium derived from non-activated microglia enhanced OPC survival and maturation through increase of PDGF-a receptor-signaling pathway and modulation of NF-kB activation (Nicholas et al., 2001). The same authors identified insulin-like growth factor-2 (IGF-2) to be an active promoter of oligodendrocyte survival, present in both conditioned media of non-activated and interferon gamma (IFN $\gamma$ )-exposed microglia (Nicholas et al., 2002). Microglia can also promote OPC differentiation via galectin-3 but not galectin1. Cultured OPCs exposed to conditioned medium from WT microglia had increased expression of MBP, while exposure of OPCs to conditioned medium obtained from galectin-3 deficient microglia resulted in decreased number of $\mathrm{MPB}^{+}$cells (Pasquini et al., 2011). Galectin-3 expression on microglia has also been claimed to control OPC differentiation in vivo and to contribute to remyelination in a model of cuprizone induced-demyelination (Hoyos et al., 2014). On the other hand, galectin-1 biding to CD45 on the surface of microglia has been shown decrease their pro-inflammatory polarization, which attenuated myelin loss and neurodegeneration in the spinal cord of EAE mice (Starossom et al., 2012). Paralleling these findings, using the $\mathrm{Cx} 3 \mathrm{cr} 1$ promoter to drive Cre recombinase expression only in microglia, it has been shown that the tyrosine TAK1 plays a crucial role in demyelination during EAE (Goldmann et al., 2013). Conditional ablation of microglial TAK1 largely attenuated myelin damage and disease severity in mice with EAE, an effect claimed to occur through defective recruitment of immune cell infiltrates, especially in the spinal cord (Goldmann et al., 2013).

The iron status of microglia is also important for oligodendrocyte survival. Increasing the iron load promotes the release of $\mathrm{H}$-ferritin by microglia and incubation of oligodendrocyte cultures with conditioned medium of ironloaded microglia increases the survival of these cultures (Zhang et al., 2006). In line with this, knocking down H-ferritin abrogated the trophic effect of the conditioned medium from iron-loaded microglia on oligodendrocyte cultures (Zhang et al., 2006).

Conditioned medium of non-activated microglia cultures was compared with that of astrocytes to evaluate their effect in OPC proliferation and differentiation. The results showed that astrocyte-conditioned medium was more efficient in promoting 
OPC proliferation, while microglia-conditioned medium accelerated oligodendrocyte differentiation more efficiently than that of astrocytes. Analysis of the media composition revealed that astrocyte-conditioned medium had increased levels of PDGF-AA, FGF2, FGF2 binding protein, CNTF, growth hormone, TIMP-1 and thrombospondin. In contrast, levels of IGF-1, E-selectin, fractalkine (CX3CL1), neuropilin-2, IL-2, IL-5, and vascular endothelial growth factor (VEGF) were significantly higher in microglia-conditioned medium. This distinct pattern of cytokines and growth factors in the conditioned medium of astrocytes and of microglia correlates with differentially activated intracellular signaling pathways in OPC exposed to the two different media (Pang et al., 2013).

In polarization conditions, such as in vitro stimulation with lipopolysaccharide (LPS), the release of cytotoxic effectors by both astrocytes and microglia produce the opposite effects on OPC (Pang et al., 2000). LPS-activated microglia hinders OPC differentiation by nitric oxide (NO)-dependent oxidative damage in an early phase and TNF in a later phase (Pang et al., 2010). In the presence of astrocytes, LPS-polarized microglia is toxic to differentiating oligodendrocytes via TNF signaling but not via NO-dependent oxidative damage ( $\mathrm{Li}$ et al., 2008). Interestingly, the presence of astrocytes was claimed to quench the oxidative damage promoted by peroxynitrite, suggesting that TNF is the dominant mechanism in killing immature oligodendrocytes ( $\mathrm{Li}$ et al., 2008). Oxidative stress, induced by CD137 ligand-polarized microglia, has also been demonstrated to promote oligodendrocyte apoptosis (Yeo et al., 2012). The effect of LPS-activated microglia was compared in OPC and mature oligodendrocytes in vitro and produced different outcomes. Pro-inflammatory microglia were found to reduce OPC viability (Miller et al., 2007) while alternatively activated microglia were shown to upregulate the GSK3 $\beta /$ AKT signaling pathway to enhance oligodendrocyte survival (Wang et al., 2015). In another report, LPS-activated microglia were shown to enhance the proliferation of $\mathrm{Golli}^{+} \mathrm{OPC}$ in purified cultures (Filipovic and Zecevic, 2005) while Taylor and colleagues demonstrated that the conditioned medium of LPS-activated microglia decreased OPC proliferation globally (Taylor et al., 2010). Although LPS-polarized microglia increased the survival of mature oligodendrocytes in primary cultures (Miller et al., 2007), LPS activation of microglia in an ex vivo cerebellar organotypic culture model was shown to induce extensive demyelination via TNF production (Di Penta et al., 2013). As expected, the LPS effect in promoting oligodendrocyte toxicity is completely dependent on the expression of the LPS receptor TLR4 on microglia (Lehnardt et al., 2002). Furthermore, activated microglia accumulate in the early postnatal SVZ region and enhance oligodendrogenesis via released cytokines, such as TNF, IL-1 $\beta$, IL-6, and IFN $\gamma$ (Shigemoto-Mogami et al., 2014).

Microglia have also been shown to induce chemotaxis of OPC in culture. This effect is mediated by microglial secretion of hepatocyte growth factor when cultures are exposed to TGF $\beta$ (Lalive et al., 2005). IFN $\gamma$-exposed microglia can promote oligodendrogenesis; in this case, the microglial effect was highly correlated with IFN $\gamma$ dosage, with high IFN $\gamma$ doses preventing oligodendrocyte differentiation (Butovsky et al., 2006) and low
IFN $\gamma$ doses being supportive of oligodendrocyte generation (Butovsky et al., 2006). The effect of microglia polarized with high dose IFN $\gamma$ could be reverted by exposing these cells to IL-4 (Butovsky et al., 2006). Besides, in chronic EAE, delivery of IL-4-polarized microglia to the CNS parenchyma, via injection into the third ventricle, could enhance oligodendrocyte differentiation and attenuate disease severity (Butovsky et al., 2006).

In remyelination, microglia have also been shown to play dual roles. Microglia expressing the CCR5 receptor were identified within early remyelinating lesions in patients at early stages of MS, suggesting a possible role for these cells in initiating remyelination (Trebst et al., 2008). Myelin repair is also influenced by microglia. Using the LysM promoter to ablate chondroitin sulfate proteoglycan 4 it has been shown that this molecule in microglia plays a significant role in promoting myelin repair after lysolecithin-induced demyelination (Kucharova and Stallcup, 2015). The phenotype of activated microglia was also shown to influence its beneficial role in efficient remyelination. Miron and colleagues found that the process of remyelination was dependent on microglia changing from an M1- to an M2-dominant response in the lysolecithininduced demyelination model. Oligodendrocyte differentiation was enhanced with M2 microglia-conditioned medium in vitro and impaired in vivo following intra-lesional depletion of M2 microglia. Activin-A was identified to be one important mediator of the oligodendrocyte differentiation-promoting effect of M2 microglia (Miron et al., 2013). The M2 polarization of microglia induced by inhibiting class I/II histone deacetylases (Wang et al., 2015) or by treatment with Omega-3 polyunsaturated fatty acids (Chen et al., 2014), was also claimed to increase the preservation of myelin homeostasis after injury to the white matter caused by traumatic brain injury or cuprizone intoxication.

\section{Microglia Phagocytosis of Myelin Debris during Myelin Damage}

Another important aspect of microglia in remyelination concerns its role in the clearance of myelin debris upon myelin injury. Myelin removal is a critical step in the remyelination process. To be effective, myelin debris must be cleared from the injury site (Kotter et al., 2006) and microglia have been recognized to play an active and beneficial role in this process (Neumann et al., 2009). Myelin clearance by microglia after cuprizoneinduced demyelination was found to depend on the expression of microglial triggering receptor expressed on myeloid cells 2 (TREM2), a surface receptor that binds polyanions, such as dextran sulfate and bacterial LPS, and activates downstream signaling cascades through the adapter DAP12 (Poliani et al., 2015). This study showed that TREM2 is required for promoting microglial expansion in response to myelin damage. Moreover, a subpopulation of microglia was identified to be responsible for producing IFN $\beta$ in demyelinated lesions of EAE, a commonly used cytokine to treat RRMS. IFN $\beta$-producing microglia are closely associated with myelin debris in the injured CNS at the peak of EAE and treatment of naïve microglia with IFN $\beta$ improved removal of myelin debris in demyelinated organotypic 
cultures (Kocur et al., 2015). In the cuprizone model, astrocytes are thought to recruit microglia to the lesion site in order to phagocyte and clear damaged myelin, a process regulated by the chemokine CXCL10. In the absence of astrocytes and, consequently, microglia recruitment, removal of myelin debris is significantly delayed inhibiting OPC proliferation and remyelination (Skripuletz et al., 2013). In line with this, it has been shown that the clearance of myelin debris by microglia can be blocked in $\mathrm{Cx} 3 \mathrm{cr} 1$-deficient mice, which have a clear deficit in microglial phagocytosis and exhibit persistent myelin deficits that correlate with a deficiency in OPC recruitment. On the other hand, the tyrosine kinase Syk has been shown to sensitize cultured microglia to phagocyte myelin (Hadas et al., 2012). These data reinforce the important role microglia play in myelin clearance and their impact in proper remyelination (Lampron et al., 2015). Myelin can also down-regulate its own phagocytosis by microglia through CD47-SIRPa, suggesting that the same mechanism that protects myelin as "self" antigen from phagocytosis may turn disadvantageous when clearance of degenerated myelin is necessary (Gitik et al., 2011).

\section{REFERENCES}

Albrecht, P. J., Murtie, J. C., Ness, J. K., Redwine, J. M., Enterline, J. R., Armstrong, R. C., et al. (2003). Astrocytes produce CNTF during the remyelination phase of viral-induced spinal cord demyelination to stimulate FGF-2 production. Neurobiol. Dis. 13, 89-101. doi: 10.1016/S0969-9961(03) 00019-6

Anderson, M. A., Burda, J. E., Ren, Y., Ao, Y., O'shea, T. M., Kawaguchi, R., et al. (2016). Astrocyte scar formation aids central nervous system axon regeneration. Nature 532, 195-200. doi: 10.1038/nature17623

Andriezen, W. L. (1893). The Neuroglia Elements in the Human Brain. Br. Med. J. 2, 227-230. doi: 10.1136/bmj.2.1700.227

Argaw, A. T., Asp, L., Zhang, J., Navrazhina, K., Pham, T., Mariani, J. N., et al. (2012). Astrocyte-derived VEGF-A drives blood-brain barrier disruption in CNS inflammatory disease. J. Clin. Invest. 122, 2454-2468. doi: $10.1172 /$ JCI 60842

Argaw, A. T., Gurfein, B. T., Zhang, Y., Zameer, A., and John, G. R. (2009). VEGF-mediated disruption of endothelial CLN-5 promotes bloodbrain barrier breakdown. Proc. Natl. Acad. Sci. U.S.A. 106, 1977-1982. doi: 10.1073/pnas.0808698106

Argaw, A. T., Zhang, Y., Snyder, B. J., Zhao, M. L., Kopp, N., Lee, S. C., et al. (2006). IL-1beta regulates blood-brain barrier permeability via reactivation of the hypoxia-angiogenesis program. J. Immunol. 177, 5574-5584. doi: 10.4049/jimmunol.177.8.5574

Back, S. A., Tuohy, T. M., Chen, H., Wallingford, N., Craig, A., Struve, J., et al. (2005). Hyaluronan accumulates in demyelinated lesions and inhibits oligodendrocyte progenitor maturation. Nat. Med. 11, 966-972. doi: $10.1038 / \mathrm{nm} 1279$

Bannerman, P., Hahn, A., Soulika, A., Gallo, V., and Pleasure, D. (2007a). Astrogliosis in EAE spinal cord: derivation from radial glia, and relationships to oligodendroglia. Glia 55, 57-64. doi: 10.1002/glia.20437

Bannerman, P., Horiuchi, M., Feldman, D., Hahn, A., Itoh, A., See, J., et al. (2007b). GluR2-free alpha-amino-3-hydroxy-5-methyl-4-isoxazolepropionate receptors intensify demyelination in experimental autoimmune encephalomyelitis. J. Neurochem. 102, 1064-1070. doi: 10.1111/j.1471-4159.2007. 04612.x

Barnett, M. H., and Prineas, J. W. (2004). Relapsing and remitting multiple sclerosis: pathology of the newly forming lesion. Ann. Neurol. 55, 458-468. doi: 10.1002/ana.20016

\section{CONCLUDING REMARKS}

Homeostasis of the CNS myelination depends on the crosstalk between oligodendrocytes, astrocytes, and microglia. Understanding the nature and complex dynamics of such interactions, which can play both beneficial and detrimental roles during damage and repair, will increase our knowledge into demyelinating diseases, and may help us to devise novel and more holistic ways to manipulate and improve remyelination.

\section{AUTHOR CONTRIBUTIONS}

$\mathrm{HD}, \mathrm{CP}$, and RS contributed equally to this work.

\section{FUNDING}

HD, CP and RS are supported with fellowships funded by Fundação para a Ciência e Tecnologia (FCT) (references SFRH/BPD/90268/2012 to HD, SFRH/BPD/91962/2012 to CP and SFRH/BPD/91833/2012 to RS).

Barres, B. A. (2008). The mystery and magic of glia: a perspective on their roles in health and disease. Neuron 60, 430-440. doi: 10.1016/j.neuron.2008.10.013

Bauer, M., Brakebusch, C., Coisne, C., Sixt, M., Wekerle, H., Engelhardt, B., et al. (2009). Betal integrins differentially control extravasation of inflammatory cell subsets into the CNS during autoimmunity. Proc. Natl. Acad. Sci. U.S.A. 106, 1920-1925. doi: 10.1073/pnas.0808909106

Bauer, N. G., Richter-Landsberg, C., and Ffrench-Constant, C. (2009). Role of the oligodendroglial cytoskeleton in differentiation and myelination. Glia 57, 1691-1705. doi: 10.1002/glia.20885

Benninger, Y., Colognato, H., Thurnherr, T., Franklin, R. J., Leone, D. P., Atanasoski, S., et al. (2006). Betal-integrin signaling mediates premyelinating oligodendrocyte survival but is not required for CNS myelination and remyelination. J. Neurosci. 26, 7665-7673. doi: 10.1523/JNEUROSCI.044406.2006

Bhat, S., and Pfeiffer, S. E. (1986). Stimulation of oligodendrocytes by extracts from astrocyte-enriched cultures. J. Neurosci. Res. 15, 19-27. doi: 10.1002/jnr.490150103

Birey, F., Kloc, M., Chavali, M., Hussein, I., Wilson, M., Christoffel, D. J., et al. (2015). Genetic and stress-induced loss of NG2 Glia triggers emergence of depressive-like behaviors through reduced secretion of FGF2. Neuron 88, 941-956. doi: 10.1016/j.neuron.2015.10.046

Blakemore, W. F., Gilson, J. M., and Crang, A. J. (2003). The presence of astrocytes in areas of demyelination influences remyelination following transplantation of oligodendrocyte progenitors. Exp. Neurol. 184, 955-963. doi: 10.1016/S00144886(03)00347-9

Bogler, O., Wren, D., Barnett, S. C., Land, H., and Noble, M. (1990). Cooperation between two growth factors promotes extended self-renewal and inhibits differentiation of oligodendrocyte-type-2 astrocyte (O-2A) progenitor cells. Proc. Natl. Acad. Sci. U.S.A. 87, 6368-6372. doi: 10.1073/pnas.87. 16.6368

Boyd, A., Zhang, H., and Williams, A. (2013). Insufficient OPC migration into demyelinated lesions is a cause of poor remyelination in MS and mouse models. Acta Neuropathol. 125, 841-859. doi: 10.1007/s00401-01 3-1112-y

Brambilla, R., Morton, P. D., Ashbaugh, J. J., Karmally, S., Lambertsen, K. L., and Bethea, J. R. (2014). Astrocytes play a key role in EAE pathophysiology by orchestrating in the CNS the inflammatory response of resident and peripheral immune cells and by suppressing remyelination. Glia 62, 452-467. doi: 10.1002/glia.22616 
Brambilla, R., Persaud, T., Hu, X., Karmally, S., Shestopalov, V. I., Dvoriantchikova, G., et al. (2009). Transgenic inhibition of astroglial NF-kappa B improves functional outcome in experimental autoimmune encephalomyelitis by suppressing chronic central nervous system inflammation. J. Immunol. 182, 2628-2640. doi: 10.4049/jimmunol.0802954

Butovsky, O., Ziv, Y., Schwartz, A., Landa, G., Talpalar, A. E., Pluchino, S., et al. (2006). Microglia activated by IL-4 or IFN-gamma differentially induce neurogenesis and oligodendrogenesis from adult stem/progenitor cells. Mol. Cell Neurosci. 31, 149-160. doi: 10.1016/j.mcn.2005.10.006

Chan, W. Y., Kohsaka, S., and Rezaie, P. (2007). The origin and cell lineage of microglia-New concepts. Brain Res. Rev. 53, 344-354. doi: 10.1016/j.brainresrev.2006.11.002

Chang, S. H., Park, H., and Dong, C. (2006). Act1 adaptor protein is an immediate and essential signaling component of interleukin-17 receptor. J. Biol. Chem. 281, 35603-35607. doi: 10.1074/jbc.C600256200

Chen, S., Zhang, H., Pu, H., Wang, G., Li, W., Leak, R. K., et al. (2014). n-3 PUFA supplementation benefits microglial responses to myelin pathology. Sci. Rep. 4:7458. doi: $10.1038 /$ srep 07458

Choi, B. H. (1981). Radial glia of developing human fetal spinal cord: Golgi, immunohistochemical and electron microscopic study. Brain Res. 227, 249-267. doi: 10.1016/0165-3806(81)90112-7

Clarke, L. E., Young, K. M., Hamilton, N. B., Li, H., Richardson, W. D., and Attwell, D. (2012). Properties and fate of oligodendrocyte progenitor cells in the corpus callosum, motor cortex, and piriform cortex of the mouse. J. Neurosci. 32, 8173-8185. doi: 10.1523/JNEUROSCI.0928-12.2012

Clemente, D., Ortega, M. C., Melero-Jerez, C., and De Castro, F. (2013). The effect of glia-glia interactions on oligodendrocyte precursor cell biology during development and in demyelinating diseases. Front. Cell. Neurosci. 7:268. doi: 10.3389/fncel.2013.00268

Corley, S. M., Ladiwala, U., Besson, A., and Yong, V. W. (2001). Astrocytes attenuate oligodendrocyte death in vitro through an alpha(6) integrinlaminin-dependent mechanism. Glia 36, 281-294. doi: 10.1002/g lia.1116

Correale, J., and Farez, M. F. (2015). The role of astrocytes in multiple sclerosis progression. Front. Neurol. 6:180. doi: 10.3389/fneur.2015.00180

Crocker, S. J., Whitmire, J. K., Frausto, R. F., Chertboonmuang, P., Soloway, P. D., Whitton, J. L., et al. (2006). Persistent macrophage/microglial activation and myelin disruption after experimental autoimmune encephalomyelitis in tissue inhibitor of metalloproteinase-1-deficient mice. Am. J. Pathol. 169, 2104-2116. doi: 10.2353/ajpath.2006.060626

del Río-Hortega, P. (1928). Tercera aportación al conocimiento morfológico e interpretación funcional de la oligodendroglía. Mem. Real Soc. Esp. Hist. Nat. $14,5-122$.

Di Bello, I. C., Dawson, M. R., Levine, J. M., and Reynolds, R. (1999). Generation of oligodendroglial progenitors in acute inflammatory demyelinating lesions of the rat brain stem is associated with demyelination rather than inflammation. J. Neurocytol. 28, 365-381. doi: 10.1023/A:1007069815302

Di Penta, A., Moreno, B., Reix, S., Fernandez-Diez, B., Villanueva, M., Errea, O., et al. (2013). Oxidative stress and proinflammatory cytokines contribute to demyelination and axonal damage in a cerebellar culture model of neuroinflammation. PLoS ONE 8:e54722. doi: 10.1371/journal.pone.0 054722

Didier, N., Romero, I. A., Creminon, C., Wijkhuisen, A., Grassi, J., and Mabondzo, A. (2003). Secretion of interleukin-1beta by astrocytes mediates endothelin1 and tumour necrosis factor-alpha effects on human brain microvascular endothelial cell permeability. J. Neurochem. 86, 246-254. doi: 10.1046/j.14714159.2003.01829.x

Dong, Y., and Benveniste, E. N. (2001). Immune function of astrocytes. Glia 36, 180-190. doi: 10.1002/glia.1107

Fabriek, B. O., Zwemmer, J. N., Teunissen, C. E., Dijkstra, C. D., Polman, C. H., Laman, J. D., et al. (2005). In vivo detection of myelin proteins in cervical lymph nodes of MS patients using ultrasound-guided fine-needle aspiration cytology. J. Neuroimmunol. 161, 190-194. doi: 10.1016/j.jneuroim.2004.12.018

Fancy, S. P. J., Zhao, C., and Franklin, R. J. M. (2004). Increased expression of Nkx2.2 and Olig2 identifies reactive oligodendrocyte progenitor cells responding to demyelination in the adult CNS. Mol. Cell. Neurosci. 27, 247-254. doi: $10.1016 /$ j.men.2004.06.015
Fawcett, J. W., and Asher, R. A. (1999). The glial scar and central nervous system repair. Brain Res. Bull. 49, 377-391. doi: 10.1016/S0361-9230(99)00072-6

Filipovic, R., and Zecevic, N. (2005). Lipopolysaccharide affects Golli expression and promotes proliferation of oligodendrocyte progenitors. Glia 49, 457-466. doi: $10.1002 /$ glia. 20125

Franklin, R. J., Crang, A. J., and Blakemore, W. F. (1991). Transplanted type-1 astrocytes facilitate repair of demyelinating lesions by host oligodendrocytes in adult rat spinal cord. J. Neurocytol. 20, 420-430. doi: 10.1007/BF01355538

Franklin, R. J., and Goldman, S. A. (2015). Glia disease and repair-remyelination. Cold Spring Harb. Perspect. Biol. 7:a020594. doi: 10.1101/cshperspect.a020594

Funfschilling, U., Supplie, L. M., Mahad, D., Boretius, S., Saab, A. S., Edgar, J., et al (2012). Glycolytic oligodendrocytes maintain myelin and long-term axonal integrity. Nature 485, 517-521. doi: 10.1038/nature11007

Gard, A. L., Burrell, M. R., Pfeiffer, S. E., Rudge, J. S., and Williams, W. C. II (1995). Astroglial control of oligodendrocyte survival mediated by PDGF and leukemia inhibitory factor-like protein. Development 121, 2187-2197.

Gimenez, M. A., Sim, J. E., and Russell, J. H. (2004). TNFR1-dependent VCAM-1 expression by astrocytes exposes the CNS to destructive inflammation. J. Neuroimmunol. 151, 116-125. doi: 10.1016/j.jneuroim.2004. 02.012

Gitik, M., Liraz-Zaltsman, S., Oldenborg, P. A., Reichert, F., and Rotshenker, S. (2011). Myelin down-regulates myelin phagocytosis by microglia and macrophages through interactions between CD47 on myelin and SIRPalpha (signal regulatory protein-alpha) on phagocytes. J. Neuroinflammation 8:24. doi: $10.1186 / 1742-2094-8-24$

Goddard, D. R., Berry, M., and Butt, A. M. (1999). In vivo actions of fibroblast growth factor-2 and insulin-like growth factor-I on oligodendrocyte development and myelination in the central nervous system. J. Neurosci. Res. $57,74-85$.

Goldmann, T., Wieghofer, P., Muller, P. F., Wolf, Y., Varol, D., Yona, S., et al. (2013). A new type of microglia gene targeting shows TAK1 to be pivotal in CNS autoimmune inflammation. Nat. Neurosci. 16, 1618-1626. doi: $10.1038 / \mathrm{nn} .3531$

Gu, C., Wu, L., and Li, X. (2013). IL-17 family: cytokines, receptors and signaling. Cytokine 64, 477-485. doi: 10.1016/j.cyto.2013.07.022

Hadas, S., Spira, M., Hanisch, U. K., Reichert, F., and Rotshenker, S. (2012). Complement receptor-3 negatively regulates the phagocytosis of degenerated myelin through tyrosine kinase Syk and cofilin. J. Neuroinflammation 9:166. doi: 10.1186/1742-2094-9-166

Hamilton, S. P., and Rome, L. H. (1994). Stimulation of in vitro myelin synthesis by microglia. Glia 11, 326-335. doi: 10.1002/glia.440110405

Hammond, T. R., Gadea, A., Dupree, J., Kerninon, C., Nait-Oumesmar, B., Aguirre, A., et al. (2014). Astrocyte-derived endothelin-1 inhibits remyelination through notch activation. Neuron 81, 588-602. doi: 10.1016/j.neuron.2013. 11.015

Hammond, T. R., Mcellin, B., Morton, P. D., Raymond, M., Dupree, J., and Gallo, V. (2015). Endothelin-B receptor activation in astrocytes regulates the rate of oligodendrocyte regeneration during remyelination. Cell Rep. 13, 2090-2097. doi: 10.1016/j.celrep.2015.11.002

Hanisch, U. K., and Kettenmann, H. (2007). Microglia: active sensor and versatile effector cells in the normal and pathologic brain. Nat. Neurosci. 10, 1387-1394. doi: $10.1038 / \mathrm{nn} 1997$

Hardin-Pouzet, H., Krakowski, M., Bourbonniere, L., Didier-Bazes, M., Tran, E., and Owens, T. (1997). Glutamate metabolism is down-regulated in astrocytes during experimental allergic encephalomyelitis. Glia 20, 79-85.

Haroon, F., Drogemuller, K., Handel, U., Brunn, A., Reinhold, D., Nishanth, G., et al. (2011). Gp130-dependent astrocytic survival is critical for the control of autoimmune central nervous system inflammation. J. Immunol. 186, 6521-6531. doi: 10.4049/jimmunol.1001135

Herculano-Houzel, S. (2014). The glia/neuron ratio: how it varies uniformly across brain structures and species and what that means for brain physiology and evolution. Glia 62, 1377-1391. doi: 10.1002/glia.22683

Holley, J. E., Gveric, D., Newcombe, J., Cuzner, M. L., and Gutowski, N. J. (2003). Astrocyte characterization in the multiple sclerosis glial scar. Neuropathol. Appl. Neurobiol. 29, 434-444. doi: 10.1046/j.1365-2990.2003.00491.x

Hoyos, H. C., Rinaldi, M., Mendez-Huergo, S. P., Marder, M., Rabinovich, G. A., Pasquini, J. M., et al. (2014). Galectin-3 controls the response of microglial cells 
to limit cuprizone-induced demyelination. Neurobiol. Dis. 62, 441-455. doi: 10.1016/j.nbd.2013.10.023

Huang, D. R., Wang, J., Kivisakk, P., Rollins, B. J., and Ransohoff, R. M. (2001). Absence of monocyte chemoattractant protein 1 in mice leads to decreased local macrophage recruitment and antigen-specific T helper cell type 1 immune response in experimental autoimmune encephalomyelitis. J. Exp. Med. 193, 713-726. doi: 10.1084/jem.193.6.713

Hughes, E. G., Kang, S. H., Fukaya, M., and Bergles, D. E. (2013). Oligodendrocyte progenitors balance growth with self-repulsion to achieve homeostasis in the adult brain. Nat. Neurosci. 16, 668-676. doi: 10.1038/nn.3390

Iacobas, S., and Iacobas, D. A. (2010). Astrocyte proximity modulates the myelination gene fabric of oligodendrocytes. Neuron Glia Biol. 6, 157-169. doi: $10.1017 /$ S1740925X10000220

Ishibashi, T., Dakin, K. A., Stevens, B., Lee, P. R., Kozlov, S. V., Stewart, C. L., et al. (2006). Astrocytes promote myelination in response to electrical impulses. Neuron 49, 823-832. doi: 10.1016/j.neuron.2006.02.006

Jovanovic, D. V., Di Battista, J. A., Martel-Pelletier, J., Jolicoeur, F. C., He, Y., Zhang, M., et al. (1998). IL-17 stimulates the production and expression of proinflammatory cytokines, IL-beta and TNF-alpha, by human macrophages. J. Immunol. 160, 3513-3521.

Kang, S. H., Fukaya, M., Yang, J. K., Rothstein, J. D., and Bergles, D. E. (2010). NG2+ CNS glial progenitors remain committed to the oligodendrocyte lineage in postnatal life and following neurodegeneration. Neuron 68, 668-681. doi: 10.1016/j.neuron.2010.09.009

Kang, Z., Altuntas, C. Z., Gulen, M. F., Liu, C., Giltiay, N., Qin, H., et al. (2010). Astrocyte-restricted ablation of interleukin-17-induced Act1-mediated signaling ameliorates autoimmune encephalomyelitis. Immunity 32, 414-425. doi: 10.1016/j.immuni.2010.03.004

Kessaris, N., Pringle, N., and Richardson, W. D. (2008). Specification of CNS glia from neural stem cells in the embryonic neuroepithelium. Philos. Trans. R. Soc. Lond. B Biol. Sci. 363, 71-85. doi: 10.1098/rstb.2006.2013

Kipp, M., Victor, M., Martino, G., and Franklin, R. J. (2012). Endogeneous remyelination: findings in human studies. CNS Neurol. Disord. Drug Targets 11, 598-609. doi: 10.2174/187152712801661257

Kocur, M., Schneider, R., Pulm, A. K., Bauer, J., Kropp, S., Gliem, M., et al. (2015). IFNbeta secreted by microglia mediates clearance of myelin debris in CNS autoimmunity. Acta Neuropathol Commun 3, 20. doi: 10.1186/s40478015-0192-4

Komiyama, Y., Nakae, S., Matsuki, T., Nambu, A., Ishigame, H., Kakuta, S., et al. (2006). IL-17 plays an important role in the development of experimental autoimmune encephalomyelitis. J. Immunol. 177, 566-573. doi: 10.4049/jimmunol.177.1.566

Kooi, E. J., Van Horssen, J., Witte, M. E., Amor, S., Bø, L., Dijkstra, C. D., et al. (2009). Abundant extracellular myelin in the meninges of patients with multiple sclerosis. Neuropathol. Appl. Neurobiol. 35, 283-295. doi: 10.1111/j.13652990.2008.00986.x

Kotter, M. R., Li, W. W., Zhao, C., and Franklin, R. J. (2006). Myelin impairs CNS remyelination by inhibiting oligodendrocyte precursor cell differentiation. $J$. Neurosci. 26, 328-332. doi: 10.1523/JNEUROSCI.2615-05.2006

Krumbholz, M., Theil, D., Derfuss, T., Rosenwald, A., Schrader, F., Monoranu, C. M., et al. (2005). BAFF is produced by astrocytes and up-regulated in multiple sclerosis lesions and primary central nervous system lymphoma. J. Exp. Med. 201, 195-200. doi: 10.1084/jem.20041674

Kucharova, K., and Stallcup, W. B. (2015). NG2-proteoglycan-dependent contributions of oligodendrocyte progenitors and myeloid cells to myelin damage and repair. J. Neuroinflammation 12, 161. doi: 10.1186/s12974-0150385-6

Kumar, S., Biancotti, J. C., Yamaguchi, M., and De Vellis, J. (2007). Combination of growth factors enhances remyelination in a cuprizone-induced demyelination mouse model. Neurochem. Res. 32, 783-797. doi: 10.1007/s11064-0 06-9208-6

Lalive, P. H., Paglinawan, R., Biollaz, G., Kappos, E. A., Leone, D. P., Malipiero, U., et al. (2005). TGF-beta-treated microglia induce oligodendrocyte precursor cell chemotaxis through the HGF-c-Met pathway. Eur. J. Immunol. 35, 727-737. doi: 10.1002/eji.200425430

Lampron, A., Larochelle, A., Laflamme, N., Prefontaine, P., Plante, M. M., Sanchez, M. G., et al. (2015). Inefficient clearance of myelin debris by microglia impairs remyelinating processes. J. Exp. Med. 212, 481-495. doi: 10.1084/jem.20141656
Lau, L. W., Keough, M. B., Haylock-Jacobs, S., Cua, R., Doring, A., Sloka, S., et al. (2012). Chondroitin sulfate proteoglycans in demyelinated lesions impair remyelination. Ann. Neurol. 72, 419-432. doi: 10.1002/ana. 23599

Lehnardt, S., Lachance, C., Patrizi, S., Lefebvre, S., Follett, P. L., Jensen, F. E., et al. (2002). The toll-like receptor TLR4 is necessary for lipopolysaccharide-induced oligodendrocyte injury in the CNS. J. Neurosci. 22, 2478-2486.

Levine, J. M., Reynolds, R., and Fawcett, J. W. (2001). The oligodendrocyte precursor cell in health and disease. Trends Neurosci. 24, 39-47. doi: 10.1016/S0166-2236(00)01691-X

Levine, J. M., Stincone, F., and Lee, Y. S. (1993). Development and differentiation of glial precursor cells in the rat cerebellum. Glia 7, 307-321. doi: 10.1002/glia.440070406

Li, J., Ramenaden, E. R., Peng, J., Koito, H., Volpe, J. J., and Rosenberg, P. A. (2008). Tumor necrosis factor alpha mediates lipopolysaccharide-induced microglial toxicity to developing oligodendrocytes when astrocytes are present. J. Neurosci. 28, 5321-5330. doi: 10.1523/JNEUROSCI.3995-07.2008

Li, X., Commane, M., Nie, H., Hua, X., Chatterjee-Kishore, M., Wald, D., et al. (2000). Act1, an NF-kappa B-activating protein. Proc. Natl. Acad. Sci. U.S.A. 97, 10489-10493. doi: 10.1073/pnas.160265197

Lourenco, T., Paes De Faria, J., Bippes, C. A., Maia, J., Lopes-Da-Silva, J. A., Relvas, J. B., et al. (2016). Modulation of oligodendrocyte differentiation and maturation by combined biochemical and mechanical cues. Sci. Rep. 6:21563. doi: $10.1038 /$ srep2 1563

Lucchinetti, C., Bruck, W., Parisi, J., Scheithauer, B., Rodriguez, M., and Lassmann, H. (1999). A quantitative analysis of oligodendrocytes in multiple sclerosis lesions. A study of 113 cases. Brain 122(Pt 12), 2279-2295. doi: 10.1093/brain/122.12.2279

Lucchinetti, C., Brück, W., Parisi, J., Scheithauer, B., Rodriguez, M., and Lassmann, H. (2000). Heterogeneity of multiple sclerosis lesions: implications for the pathogenesis of demyelination. Ann. Neurol. 47, 707-717. doi: 10.1002/15318249(200006)47:6<707::AID-ANA3>3.0.CO;2-Q

Lutz, S. E., Zhao, Y., Gulinello, M., Lee, S. C., Raine, C. S., and Brosnan, C. F. (2009). Deletion of astrocyte connexins 43 and 30 leads to a dysmyelinating phenotype and hippocampal CA1 vacuolation. J. Neurosci. 29, 7743-7752. doi: 10.1523/JNEUROSCI.0341-09.2009

Markoullis, K., Sargiannidou, I., Gardner, C., Hadjisavvas, A., Reynolds, R., and Kleopa, K. A. (2012). Disruption of oligodendrocyte gap junctions in experimental autoimmune encephalomyelitis. Glia 60, 1053-1066. doi: 10.1002/glia.22334

Markoullis, K., Sargiannidou, I., Schiza, N., Roncaroli, F., Reynolds, R., and Kleopa, K. A. (2014). Oligodendrocyte gap junction loss and disconnection from reactive astrocytes in multiple sclerosis gray matter. J. Neuropathol. Exp. Neurol. 73, 865-879. doi: 10.1097/NEN.0000000000000106

Mckenzie, I. A., Ohayon, D., Li, H., Paes De Faria, J., Emery, B., Tohyama, K., et al. (2014). Motor skill learning requires active central myelination. Science 346, 318-322. doi: 10.1126/science. 1254960

McTigue, D. M., Wei, P., and Stokes, B. T. (2001). Proliferation of NG2-positive cells and altered oligodendrocyte numbers in the contused rat spinal cord. J. Neurosci. 21, 3392-3400. Available online at: http://www.jneurosci.org/ content/21/10/3392.long

Megard, I., Garrigues, A., Orlowski, S., Jorajuria, S., Clayette, P., Ezan, E., et al. (2002). A co-culture-based model of human blood-brain barrier: application to active transport of indinavir and in vivo -in vitro correlation. Brain Res. 927, 153-167. doi: 10.1016/S0006-8993(01)03337-6

Menn, B., Garcia-Verdugo, J. M., Yaschine, C., Gonzalez-Perez, O., Rowitch, D., and Alvarez-Buylla, A. (2006). Origin of oligodendrocytes in the subventricular zone of the adult brain. J. Neurosci. 26, 7907-7918. doi: 10.1523/JNEUROSCI.1299-06.2006

Messersmith, D. J., Murtie, J. C., Le, T. Q., Frost, E. E., and Armstrong, R. C. (2000). Fibroblast growth factor 2 (FGF2) and FGF receptor expression in an experimental demyelinating disease with extensive remyelination. $J$. Neurosci. Res. 62, 241-256. doi: 10.1002/1097-4547(20001015)62:2<241::AIDJNR9>3.0.CO;2-D

Miller, B. A., Crum, J. M., Tovar, C. A., Ferguson, A. R., Bresnahan, J. C., and Beattie, M. S. (2007). Developmental stage of oligodendrocytes determines their response to activated microglia in vitro. J. Neuroinflammation 4, 28. doi: $10.1186 / 1742-2094-4-28$ 
Miron, V. E., Boyd, A., Zhao, J.-W., Yuen, T. J., Ruckh, J. M., Shadrach, J. L., et al. (2013). M2 microglia and macrophages drive oligodendrocyte differentiation during CNS remyelination. Nat. Neurosci. 16, 1211-1218. doi: 10.1038/ nn.3469

Mitew, S., Hay, C. M., Peckham, H., Xiao, J., Koenning, M., and Emery, B. (2014). Mechanisms regulating the development of oligodendrocytes and central nervous system myelin. Neuroscience 276, 29-47. doi: 10.1016/j.neuroscience.2013.11.029

Monteiro De Castro, G., Deja, N. A., Ma, D., Zhao, C., and Franklin, R. J. (2015). Astrocyte activation via Stat3 signaling determines the balance of oligodendrocyte versus schwann cell remyelination. Am. J. Pathol. 185, 2431-2440. doi: 10.1016/j.ajpath.2015.05.011

Moore, C. S., Milner, R., Nishiyama, A., Frausto, R. F., Serwanski, D. R., Pagarigan, R. R., et al. (2011). Astrocytic tissue inhibitor of metalloproteinase1 (TIMP-1) promotes oligodendrocyte differentiation and enhances CNS myelination. J. Neurosci. 31, 6247-6254. doi: 10.1523/JNEUROSCI.5 474-10.2011

Moyon, S., Dubessy, A. L., Aigrot, M. S., Trotter, M., Huang, J. K., Dauphinot, L., et al. (2015). Demyelination causes adult CNS progenitors to revert to an immature state and express immune cues that support their migration. $J$. Neurosci. 35, 4-20. doi: 10.1523/JNEUROSCI.0849-14.2015

Nagy, J. I., and Rash, J. E. (2000). Connexins and gap junctions of astrocytes and oligodendrocytes in the CNS. Brain Res. Rev. 32, 29-44. doi: 10.1016/S01650173(99)00066-1

Nair, A., Frederick, T. J., and Miller, S. D. (2008). Astrocytes in multiple sclerosis: A product of their environment. Cell. Mol. Life Sci. 65, 2702-2720. doi: 10.1007/s00018-008-8059-5

Nash, B., Ioannidou, K., and Barnett, S. C. (2011a). Astrocyte phenotypes and their relationship to myelination. J. Anat. 219, 44-52. doi: 10.1111/j.14697580.2010.01330.x

Nash, B., Thomson, C. E., Linington, C., Arthur, A. T., Mcclure, J. D., Mcbride, M. W., et al. (2011b). Functional duality of astrocytes in myelination. J. Neurosci. 31, 13028-13038. doi: 10.1523/JNEUROSCI.1449-11.2011

Nave, K. A., and Werner, H. B. (2014). Myelination of the nervous system: mechanisms and functions. Annu. Rev. Cell Dev. Biol. 30, 503-533. doi: 10.1146/annurev-cellbio-100913-013101

Neumann, H., Kotter, M. R., and Franklin, R. J. (2009). Debris clearance by microglia: an essential link between degeneration and regeneration. Brain 132, 288-295. doi: 10.1093/brain/awn109

Nicholas, R. S., Stevens, S., Wing, M. G., and Compston, D. A. (2002). Microgliaderived IGF-2 prevents TNFalpha induced death of mature oligodendrocytes in vitro. J. Neuroimmunol. 124, 36-44. doi: 10.1016/S0165-5728(02)0 0011-5

Nicholas, R. S., Wing, M. G., and Compston, A. (2001). Nonactivated microglia promote oligodendrocyte precursor survival and maturation through the transcription factor NF-kappa B. Eur. J. Neurosci. 13, 959-967. doi: 10.1046/j.0953-816x.2001.01470.x

Nicol, B., Salou, M., Laplaud, D. A., and Wekerle, H. (2015). The autoimmune concept of multiple sclerosis. Presse Med. 44, e103-e112. doi: 10.1016/j.lpm.2015.02.009

Nishiyama, A., Lin, X. H., Giese, N., Heldin, C. H., and Stallcup, W. B. (1996). Colocalization of NG2 proteoglycan and PDGF alpha-receptor on O2A progenitor cells in the developing rat brain. J. Neurosci. Res. 43, 299-314.

Noble, M., and Murray, K. (1984). Purified astrocytes promote the in vitro division of a bipotential glial progenitor cell. EMBO J. 3, 2243-2247.

Noble, M., Murray, K., Stroobant, P., Waterfield, M. D., and Riddle, P. (1988). Platelet-derived growth factor promotes division and motility and inhibits premature differentiation of the oligodendrocyte/type- 2 astrocyte progenitor cell. Nature 333, 560-562. doi: 10.1038/333560a0

Nobuta, H., Ghiani, C. A., Paez, P. M., Spreuer, V., Dong, H., Korsak, R. A., et al. (2012). STAT3-mediated astrogliosis protects myelin development in neonatal brain injury. Ann. Neurol. 72, 750-765. doi: 10.1002/ana. 23670

Nygardas, P. T., and Hinkkanen, A. E. (2002). Up-regulation of MMP-8 and MMP-9 activity in the BALB/c mouse spinal cord correlates with the severity of experimental autoimmune encephalomyelitis. Clin. Exp. Immunol. 128, 245-254. doi: 10.1046/j.1365-2249.2002.01855.x
Oh, L. Y., Goodyer, C. G., Olivier, A., and Yong, V. W. (1997). The promoting effects of bFGF and astrocyte extracellular matrix on process outgrowth by adult human oligodendrocytes are mediated by protein kinase C. Brain Res. 757, 236-244. doi: 10.1016/S0006-8993(97)00224-2

Oh, L. Y., and Yong, V. W. (1996). Astrocytes promote process outgrowth by adult human oligodendrocytes in vitro through interaction between bFGF and astrocyte extracellular matrix. Glia 17, 237-253.

Ohgoh, M., Hanada, T., Smith, T., Hashimoto, T., Ueno, M., Yamanishi, Y., et al. (2002). Altered expression of glutamate transporters in experimental autoimmune encephalomyelitis. J. Neuroimmunol. 125, 170-178. doi: 10.1016/S0165-5728(02)00029-2

Omari, K. M., John, G. R., Sealfon, S. C., and Raine, C. S. (2005). CXC chemokine receptors on human oligodendrocytes: implications for multiple sclerosis. Brain 128, 1003-1015. doi: 10.1093/brain/awh479

Orthmann-Murphy, J. L., Abrams, C. K., and Scherer, S. S. (2008). Gap junctions couple astrocytes and oligodendrocytes. J. Mol. Neurosci. 35, 101-116. doi: 10.1007/s12031-007-9027-5

Pang, Y., Cai, Z., and Rhodes, P. G. (2000). Effects of lipopolysaccharide on oligodendrocyte progenitor cells are mediated by astrocytes and microglia. $J$. Neurosci. Res. 62, 510-520.

Pang, Y., Campbell, L., Zheng, B., Fan, L., Cai, Z., and Rhodes, P. (2010). Lipopolysaccharide-activated microglia induce death of oligodendrocyte progenitor cells and impede their development. Neuroscience 166, 464-475. doi: 10.1016/j.neuroscience.2009.12.040

Pang, Y., Fan, L. W., Tien, L. T., Dai, X., Zheng, B., Cai, Z., et al. (2013). Differential roles of astrocyte and microglia in supporting oligodendrocyte development and myelination in vitro. Brain Behav. 3, 503-514. doi: 10.1002/ brb3.152

Pasquini, L. A., Millet, V., Hoyos, H. C., Giannoni, J. P., Croci, D. O., Marder, M., et al. (2011). Galectin-3 drives oligodendrocyte differentiation to control myelin integrity and function. Cell Death Differ. 18, 1746-1756. doi: $10.1038 /$ cdd. 2011.40

Patel, J. R., Williams, J. L., Muccigrosso, M. M., Liu, L., Sun, T., Rubin, J. B., et al. (2012). Astrocyte TNFR2 is required for CXCL12-mediated regulation of oligodendrocyte progenitor proliferation and differentiation within the adult CNS. Acta Neuropathol. 124, 847-860. doi: 10.1007/s00401-0 12-1034-0

Pendleton, J. C., Shamblott, M. J., Gary, D. S., Belegu, V., Hurtado, A., Malone, M. L., et al. (2013). Chondroitin sulfate proteoglycans inhibit oligodendrocyte myelination through PTPsigma. Exp. Neurol. 247, 113-121. doi: 10.1016/j.expneurol.2013.04.003

Poliani, P. L., Wang, Y., Fontana, E., Robinette, M. L., Yamanishi, Y., Gilfillan, S., et al. (2015). TREM2 sustains microglial expansion during aging and response to demyelination. J. Clin. Invest. 125, 2161-2170. doi: 10.1172/JCI 77983

Prineas, J. W., Kwon, E. E., Goldenberg, P. Z., Ilyas, A. A., Quarles, R. H., Benjamins, J. A., et al. (1989). Multiple sclerosis. Oligodendrocyte proliferation and differentiation in fresh lesions. Lab. Invest. 61, 489-503.

Prinz, M., and Priller, J. (2014). Microglia and brain macrophages in the molecular age: from origin to neuropsychiatric disease. Nat. Rev. Neurosci. 15, 300-312. doi: $10.1038 / \mathrm{nrn} 3722$

Ramón Y Cajal, S. (1909). Histologie du Système Nerveux de L’Homme \& des Vertébrés. Paris: Maloine.

Ransohoff, R. M., Hamilton, T. A., Tani, M., Stoler, M. H., Shick, H. E., Major, J. A., et al. (1993). Astrocyte expression of mRNA encoding cytokines IP-10 and JE/MCP-1 in experimental autoimmune encephalomyelitis. FASEB J. 7, 592-600.

Redwine, J. M., and Armstrong, R. C. (1998). In vivo proliferation of oligodendrocyte progenitors expressing PDGF $\alpha$ R during early remyelination. J. Neurobiol. 37, 413-428.

Relvas, J. B., Setzu, A., Baron, W., Buttery, P. C., Laflamme, S. E., Franklin, R. J., et al. (2001). Expression of dominant-negative and chimeric subunits reveals an essential role for beta1 integrin during myelination. Curr. Biol. 11, 1039-1043. doi: 10.1016/S0960-9822(01)00292-5

Richardson, W. D., Pringle, N., Mosley, M. J., Westermark, B., and Dubois-Dalcq, M. (1988). A role for platelet-derived growth factor in normal gliogenesis in the central nervous system. Cell 53, 309-319. doi: 10.1016/0092-8674(88)90392-3 
Richardson, W. D., Young, K. M., Tripathi, R. B., and Mckenzie, I. (2011). NG2glia as multipotent neural stem cells: fact or fantasy? Neuron 70, 661-673. doi: 10.1016/j.neuron.2011.05.013

Rivers, L. E., Young, K. M., Rizzi, M., Jamen, F., Psachoulia, K., Wade, A., et al. (2008). PDGFRA/NG2 glia generate myelinating oligodendrocytes and piriform projection neurons in adult mice. Nat. Neurosci. 11, 1392-1401. doi: 10.1038/nn. 2220

Robinson, S. R., Hampson, E. C., Munro, M. N., and Vaney, D. I. (1993). Unidirectional coupling of gap junctions between neuroglia. Science 262, 1072-1074. doi: 10.1126/science.8093125

Rosen, C. L., Bunge, R. P., Ard, M. D., and Wood, P. M. (1989). Type 1 astrocytes inhibit myelination by adult rat oligodendrocytes in vitro. J. Neurosci. 9, 3371-3379.

Sakurai, Y., Nishimura, D., Yoshimura, K., Tsuruo, Y., Seiwa, C., and Asou, H. (1998). Differentiation of oligodendrocyte occurs in contact with astrocyte. J. Neurosci. Res. 52, 17-26.

Selvaraju, R., Bernasconi, L., Losberger, C., Graber, P., Kadi, L., Avellana-Adalid, V., et al. (2004). Osteopontin is upregulated during in vivo demyelination and remyelination and enhances myelin formation in vitro. Mol. Cell. Neurosci. 25, 707-721. doi: 10.1016/j.mcn.2003.12.014

Shi, J., Marinovich, A., and Barres, B. A. (1998). Purification and characterization of adult oligodendrocyte precursor cells from the rat optic nerve. J. Neurosci. $18,4627-4636$

Shigemoto-Mogami, Y., Hoshikawa, K., Goldman, J. E., Sekino, Y., and Sato, K. (2014). Microglia enhance neurogenesis and oligodendrogenesis in the early postnatal subventricular zone. J. Neurosci. 34, 2231-2243. doi: 10.1523/JNEUROSCI.1619-13.2014

Silver, J., and Miller, J. H. (2004). Regeneration beyond the glial scar. Nat. Rev. Neurosci. 5, 146-156. doi: 10.1038/nrn1326

Siskova, Z., Yong, V. W., Nomden, A., Van Strien, M., Hoekstra, D., and Baron, W. (2009). Fibronectin attenuates process outgrowth in oligodendrocytes by mislocalizing MMP-9 activity. Mol. Cell. Neurosci. 42, 234-242. doi: 10.1016/j.mcn.2009.07.005

Skripuletz, T., Hackstette, D., Bauer, K., Gudi, V., Pul, R., Voss, E., et al. (2013). Astrocytes regulate myelin clearance through recruitment of microglia during cuprizone-induced demyelination. Brain 136, 147-167. doi: 10.1093/brain/aws262

Sloane, J. A., Batt, C., Ma, Y., Harris, Z. M., Trapp, B., and Vartanian, T. (2010). Hyaluronan blocks oligodendrocyte progenitor maturation and remyelination through TLR2. Proc. Natl. Acad. Sci. U.S.A. 107, 11555-11560. doi: $10.1073 /$ pnas. 1006496107

Snaidero, N., and Simons, M. (2014). Myelination at a glance. J. Cell Sci. 127, 2999-3004. doi: 10.1242/jcs.151043

Sofroniew, M. V., and Vinters, H. V. (2010). Astrocytes: biology and pathology. Acta Neuropathol. 119, 7-35. doi: 10.1007/s00401-009-0619-8

Sorensen, A., Moffat, K., Thomson, C., and Barnett, S. C. (2008). Astrocytes, but not olfactory ensheathing cells or Schwann cells, promote myelination of CNS axons in vitro. Glia 56, 750-763. doi: 10.1002/glia.20650

Soulet, D., and Rivest, S. (2008). Microglia. Curr. Biol. 18, R506-R508. doi: 10.1016/j.cub.2008.04.047

Stankoff, B., Aigrot, M.-S., Noël, F., Wattilliaux, A., Zalc, B., and Lubetzki, C. (2002). Ciliary neurotrophic factor (CNTF) enhances myelin formation: a novel role for CNTF and CNTF-related molecules. J. Neurosci. 22, 9221-9227. Available online at: http://www.jneurosci.org/content/22/21/9221.long

Starossom, S. C., Mascanfroni, I. D., Imitola, J., Cao, L., Raddassi, K., Hernandez, S. F., et al. (2012). Galectin-1 deactivates classically activated microglia and protects from inflammation-induced neurodegeneration. Immunity 37, 249-263. doi: 10.1016/j.immuni.2012.05.023

Stoffels, J. M., De Jonge, J. C., Stancic, M., Nomden, A., Van Strien, M. E., Ma, D., et al. (2013). Fibronectin aggregation in multiple sclerosis lesions impairs remyelination. Brain 136, 116-131. doi: 10.1093/brain/aws313

Stoffels, J. M., Hoekstra, D., Franklin, R. J., Baron, W., and Zhao, C. (2015). The EIIIA domain from astrocyte-derived fibronectin mediates proliferation of oligodendrocyte progenitor cells following CNS demyelination. Glia 63, 242-256. doi: 10.1002/glia.22748

Talbott, J. F., Loy, D. N., Liu, Y., Qiu, M. S., Bunge, M. B., Rao, M. S., et al. (2005). Endogenous Nkx2.2+/Olig2+ oligodendrocyte precursor cells fail to remyelinate the demyelinated adult rat spinal cord in the absence of astrocytes. Exp. Neurol. 192, 11-24. doi: 10.1016/j.expneurol.2004.05.038

Tanuma, N., Sakuma, H., Sasaki, A., and Matsumoto, Y. (2006). Chemokine expression by astrocytes plays a role in microglia/macrophage activation and subsequent neurodegeneration in secondary progressive multiple sclerosis. Acta Neuropathol. 112, 195-204. doi: 10.1007/s00401-0 06-0083-7

Taveggia, C., Thaker, P., Petrylak, A., Caporaso, G. L., Toews, A., Falls, D. L., et al. (2008). Type III neuregulin-1 promotes oligodendrocyte myelination. Glia 56, 284-293. doi: 10.1002/glia.20612

Taylor, D. L., Pirianov, G., Holland, S., Mcginnity, C. J., Norman, A. L., Reali, C., et al. (2010). Attenuation of proliferation in oligodendrocyte precursor cells by activated microglia. J. Neurosci. Res. 88, 1632-1644. doi: 10.1002/jnr. 22335

Thurnherr, T., Benninger, Y., Wu, X., Chrostek, A., Krause, S. M., Nave, K. A., et al. (2006). Cdc42 and Racl signaling are both required for and act synergistically in the correct formation of myelin sheaths in the CNS. J. Neurosci. 26, 10110-10119. doi: 10.1523/JNEUROSCI.2158-06.2006

Toft-Hansen, H., Fuchtbauer, L., and Owens, T. (2011). Inhibition of reactive astrocytosis in established experimental autoimmune encephalomyelitis favors infiltration by myeloid cells over T cells and enhances severity of disease. Glia 59, 166-176. doi: 10.1002/glia.21088

Traka, M., Podojil, J. R., Mccarthy, D. P., Miller, S. D., and Popko, B. (2016). Oligodendrocyte death results in immune-mediated CNS demyelination. Nat. Neurosci. 19, 65-74. doi: 10.1038/nn.4193

Trebst, C., König, F., Ransohoff, R., Brück, W., and Stangel, M. (2008). CCR5 expression on macrophages/microglia is associated with early remyelination in multiple sclerosis lesions. Mult. Scler. 14, 728-733. doi: $10.1177 / 1352458508089359$

Tress, O., Maglione, M., May, D., Pivneva, T., Richter, N., Seyfarth, J., et al. (2012). Panglial gap junctional communication is essential for maintenance of myelin in the CNS. J. Neurosci. 32, 7499-7518. doi: 10.1523/JNEUROSCI.03 92-12.2012

Virchow, R. (1856). Gesammelte Abhandlungen zyr Wissenschaftlischen Medizin. Frankfurt a.M: Verlag von Meidinger Sohn \& Comp.

Voigt, T. (1989). Development of glial cells in the cerebral wall of ferrets: direct tracing of their transformation from radial glia into astrocytes. J. Comp. Neurol. 289, 74-88. doi: 10.1002/cne.902890106

Wang, G., Shi, Y., Jiang, X., Leak, R. K., Hu, X., Wu, Y., et al. (2015). HDAC inhibition prevents white matter injury by modulating microglia/macrophage polarization through the GSK3beta/PTEN/Akt axis. Proc. Natl. Acad. Sci. U.S.A. 112, 2853-2858. doi: 10.1073/pnas.1501441112

Wang, Y., Cheng, X., He, Q., Zheng, Y., Kim, D. H., Whittemore, S. R., et al. (2011). Astrocytes from the contused spinal cord inhibit oligodendrocyte differentiation of adult oligodendrocyte precursor cells by increasing the expression of bone morphogenetic proteins. J. Neurosci. 31, 6053-6058. doi: 10.1523/JNEUROSCI.5524-09.2011

Watanabe, M., Toyama, Y., and Nishiyama, A. (2002). Differentiation of proliferated NG2-positive glial progenitor cells in a remyelinating lesion. $J$. Neurosci. Res. 69, 826-836. doi: 10.1002/jnr.10338

Watkins, T. A., Emery, B., Mulinyawe, S., and Barres, B. A. (2008). Distinct stages of myelination regulated by gamma-secretase and astrocytes in a rapidly myelinating CNS coculture system. Neuron 60, 555-569. doi: 10.1016/j.neuron.2008.09.011

Williams, A., Piaton, G., and Lubetzki, C. (2007). Astrocytes-friends or foes in multiple sclerosis? Glia 55, 1300-1312. doi: 10.1002/glia.20546

Yan, Y., Ding, X., Li, K., Ciric, B., Wu, S., Xu, H., et al. (2012). CNS-specific therapy for ongoing EAE by silencing IL-17 pathway in astrocytes. Mol. Ther. 20, 1338-1348. doi: 10.1038/mt.2012.12

Ye, P., Popken, G. J., Kemper, A., Mccarthy, K., Popko, B., and D'ercole, A. J. (2004). Astrocyte-specific overexpression of insulin-like growth factor-I promotes brain overgrowth and glial fibrillary acidic protein expression. $J$. Neurosci. Res. 78, 472-484. doi: 10.1002/jnr.20288

Yeo, Y. A., Martinez Gomez, J. M., Croxford, J. L., Gasser, S., Ling, E. A., and Schwarz, H. (2012). CD137 ligand activated microglia induces oligodendrocyte apoptosis via reactive oxygen species. J. Neuroinflammation 9, 173. doi: $10.1186 / 1742-2094-9-173$ 
Yeung, M. S., Zdunek, S., Bergmann, O., Bernard, S., Salehpour, M., Alkass, K., et al. (2014). Dynamics of oligodendrocyte generation and myelination in the human brain. Cell 159, 766-774. doi: 10.1016/j.cell.2014. 10.011

Zawadzka, M., Rivers, L. E., Fancy, S. P., Zhao, C., Tripathi, R., Jamen, F., et al. (2010). CNS-resident glial progenitor/stem cells produce Schwann cells as well as oligodendrocytes during repair of CNS demyelination. Cell Stem Cell 6, 578-590. doi: 10.1016/j.stem.2010.04.002

Zeger, M., Popken, G., Zhang, J., Xuan, S., Lu, Q. R., Schwab, M. H., et al. (2007). Insulin-like growth factor type 1 receptor signaling in the cells of oligodendrocyte lineage is required for normal in vivo oligodendrocyte development and myelination. Glia 55, 400-411. doi: 10.1002/gl ia. 20469

Zhang, X., Surguladze, N., Slagle-Webb, B., Cozzi, A., and Connor, J. R. (2006). Cellular iron status influences the functional relationship between microglia and oligodendrocytes. Glia 54, 795-804. doi: 10.1002/glia.20416
Zuchero, J. B., and Barres, B. A. (2013). Intrinsic and extrinsic control of oligodendrocyte development. Curr. Opin. Neurobiol. 23, 914-920. doi: 10.1016/j.conb.2013.06.005

Zuchero, J. B., and Barres, B. A. (2015). Glia in mammalian development and disease. Development 142, 3805-3809. doi: 10.1242/dev.129304

Conflict of Interest Statement: The authors declare that the research was conducted in the absence of any commercial or financial relationships that could be construed as a potential conflict of interest.

Copyright $\odot 2016$ Domingues, Portugal, Socodato and Relvas. This is an open-access article distributed under the terms of the Creative Commons Attribution License (CC $B Y)$. The use, distribution or reproduction in other forums is permitted, provided the original author(s) or licensor are credited and that the original publication in this journal is cited, in accordance with accepted academic practice. No use, distribution or reproduction is permitted which does not comply with these terms. 